\title{
Synthesis, in vitro Antimicrobial Activity, and Docking Studies of some Pyrano[2,3-c] Pyrazole Derivatives
}

\author{
Boutaina Addoum ${ }^{1 \mathbb{D}}$, Bouchra El Khalfi ${ }^{1 \mathbb{D}}$, Reda Derdak ${ }^{1 \mathbb{D}}$, Souraya Sakoui ${ }^{1 \mathbb{D}}$, Abdelhakim \\ Elmakssoudi $^{2}$ (D), Abdelaziz Soukri 1,*(D) \\ 1 Laboratory of Physiopathology, Genetics, Molecular and Biotechnology (PGMB), Department of Biology, Faculty of \\ Sciences Aïn Chock, Research Center of Health and Biotechnology, Hassan II University, B.P 5366 Maarif, Casablanca, \\ Morocco \\ 2 Laboratory of Organic Synthesis, Extraction, and Valorization, Department of Chemistry, Faculty of Sciences Aïn Chock, \\ Hassan II University, B.P 5366 Maarif, Casablanca, Morocco \\ * Correspondence: ab.soukri@gmail.com (A.S.);
}

Scopus Author ID6603581469

Received: 30.07.2021; 10.09.2021: date; Accepted: 15.09.2021; Published: 16.10.2021

\begin{abstract}
The hospital environment favors the circulation of drug-resistant bacteria. The researcher has oriented this public health problem to find an ideal tool for better patient management. Therefore, this study aims to assess the biological activity of some synthetic molecules against multidrug-resistant bacterial isolates from patients suspected of nosocomial infections. After synthesizing and characterizing five targeted compounds 5(a-e), a sensitivity test is carried out to screen their antibacterial activity via microbiological methods (diffusion and microdilution). The forgoing results confirmed that (5c) compound has better potential against all studied strains with a minimum inhibitory concentration (MIC) that varies between $6.25-50 \mathrm{mg} / \mathrm{mL}$. The lowest MIC values were observed with Klebsiella pneumonia, while the greatest value of the same parameter was obtained with L. monocytogenes. On the other side, in silico pharmacological studies like ADME and docking data were implemented for the selected compounds 5(a-e) to comprehensively understand the plausible mode of interaction with the target. Docking results indicated that the compounds $5 \mathrm{c}$ and $5 \mathrm{~b}$ have considerable binding energy towards the active site of Escherichia coli MurB and S. aureus DNA gyrase B. In vitro and in silico data have confirmed the antimicrobial potentials of the five synthetic compounds; this data can be added and supported the literature on the bioactivity of pyrano[2,3-c] pyrazole.
\end{abstract}

Keywords: Synthesis; Multiresistant; Pyrano[2,3-c] pyrazole; In-vitro; In-silico.

(C) 2021 by the authors. This article is an open-access article distributed under the terms and conditions of the Creative Commons Attribution (CC BY) license (https://creativecommons.org/licenses/by/4.0/).

\section{Introduction}

Antibiotics are considered the leading source for treating nosocomial infection (Nis) diseases. While, the uncontrolled spread of new multiresistant strains to antibiotics among Gram-negative and Gram-positive bacteria is considered a limited therapeutic option, which raises the risks of treatment failure and patient management [1]. Recently, the scientific community has been facing an alarming healthiness threat, that is, the emergence of these MDR strains and the lack of real prospects for discovering new antibiotics led us to develop other therapeutic strategies able to fight against these multidrug-resistant bacteria. For that reason, a new research field starts to take place position in medical research, namely, «synthetic drug discovery » [2]. According to the literature, many synthetic motifs are considered a superseded source for new drugs with a large spectrum of activities. Among them, we can cite the 
pyrano[2,3-c] pyrazole that displayed a prominent antibacterial [3], analgesic, antimicrobial, anticancer role [4].

Additionally, these heterocyclic compounds revealed higher antibacterial activity due to their structure [5]. In this context and to complement our previous studies on pyrano[2,3-c] pyrazole bioactivity [6], the present work envisaged discovering the relationship between the structural merger and biological activity of these compounds [7]. Firstly, we evaluated the antibacterial properties of the synthesized compounds on the in vitro growth of some microorganisms recognized as pathogen strains. We succeeded in preparing these compounds under eco-friendly conditions via the one-pot method [6,8]. Therefore, we screened their antibacterial propriety by using fast bioassays, including diffusion and microdilution [9]. Then Docking studies were performed for the five compounds to evaluate their affinity to inhibit bacterial proteins that are known as targets for some antibiotics with different mechanisms of action: inhibitors of cell wall synthesis, inhibitors of protein synthesis, inhibitors of nucleic acid synthesis, and antimetabolites [10-12]. After the molecular docking simulation and calculation of pharmacological or ADMET properties, we noticed that the in-silico data results are in harmony with the in vitro funding.

\section{Materials and Methods}

\subsection{Chemical experimental data.}

2.1.1. Synthesis and characterization of the catalyst.

\subsubsection{Instruments}

The crystalline structure of the $\mathrm{Na}_{2} \mathrm{CaP}_{2} \mathrm{O}_{7}$ was identified by using X-ray diffraction analysis (XRD). The melting point of the selected compounds was studied using a Buchi 510 device. The NMR spectra data of Hydrogen and carbon were determined via Bruker $300 \mathrm{MHz}$. The chemical shifts $(\delta)$ are expressed in ppm. Then, IR spectra of the synthesized compounds were collected using FTIR (IR Affinity - 1S, Fourier Transform Infrared Spectrophotometer, SHIMADZU). The purification of samples was acquired using analytical thin-layer chromatography, performed with Silica on TLC Alu foils purchased from Sigma Aldrich, and High-performance light chromatography (HPLC). All reactions were performed under air. Solvents and raw materials (Aldrich) were used without further purification.

\subsubsection{Method for the preparation of the catalyst.}

The synthesis of the $\mathrm{Na}_{2} \mathrm{CaP}_{2} \mathrm{O}_{7}$ has been performed using $\mathrm{Na}_{2} \mathrm{CO}_{3}, \mathrm{CaCO}_{3}$, and $\mathrm{NH}_{4} \mathrm{H}_{2} \mathrm{PO}_{4}$ (see Figure 1). These components were mixed in an agate mortar and then gradually heated in a porcelain crucible. Then, the synthesis of $\mathrm{Na}_{2} \mathrm{CaP}_{2} \mathrm{O}_{7}$ particles was confirmed by powder XRD, IR, SEM, and TEM studies. The steps of $\mathrm{Na}_{2} \mathrm{CaPO}_{7}$ synthesis are summarized in figure 1. 


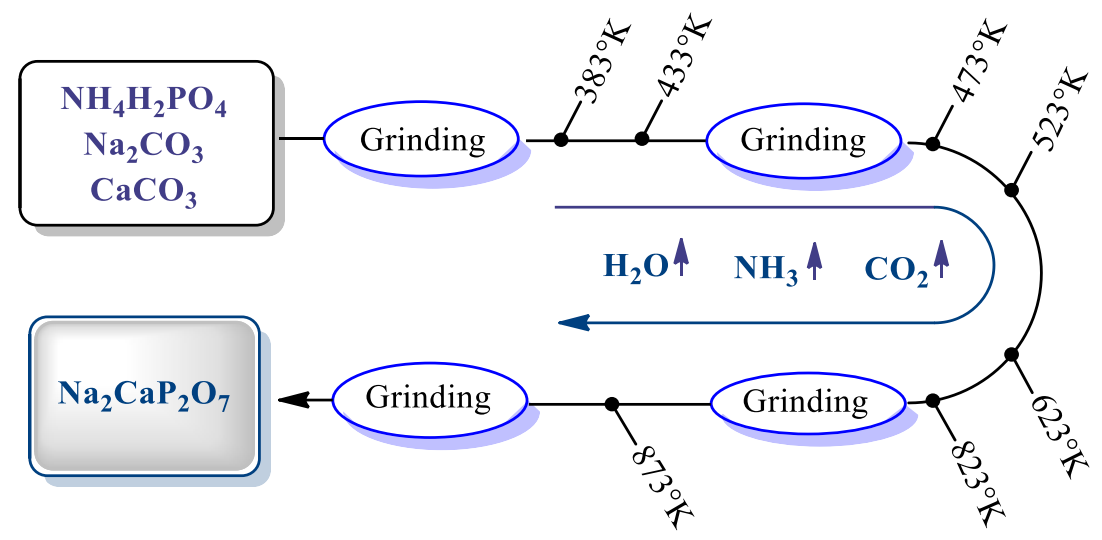

Figure 1. Steps of $\mathrm{Na}_{2} \mathrm{CaP}_{2} \mathrm{O}_{7}$ synthesis.

\subsubsection{XDR of the catalyst.}

The powder obtained was studied using an X-ray diffractometer, and the diffraction pattern was recorded via the Bruker D8 Advance diffractogram. The obtained spectrum and the crystallographic data of the catalyst $\mathrm{Na}_{2} \mathrm{CaP}_{2} \mathrm{O}_{7}$ are reproduced in Figure S17and Table S1.

\subsubsection{Infrared spectra.}

After the synthesis of the catalyst, we proceed to the characterization via the IR method, and the infrared spectrum of the diphosphate $\mathrm{Na}_{2} \mathrm{CaP}_{2} \mathrm{O}_{7}$ in powder form is shown in Figure S18 and Table S2.

\subsubsection{TEM and SEM.}

During this study, the surface morphology of $\mathrm{Na}_{2} \mathrm{CaP}_{2} \mathrm{O}_{7}$ was also carried out using the HIROX SH-4000M scanning electron microscope. To visualize the microstructure of this catalyst, the authors used Transmission Electronic Microscopy (TEM), which is an FEI microscope operated at $120 \mathrm{kV}$ (see Figure S19 and S20.)

\subsubsection{The general protocol of pyrano[2,3-c] pyrazoles synthesis.}

The pyrano[2,3-c] pyrazole product was prepared according to the method of Zahouily et al. reported in the literature[13]. Firstly, the catalyst $\mathrm{Na}_{2} \mathrm{CaP}_{2} \mathrm{O}_{7}(20 \mathrm{~mol} \%)$ was added to a mixture of the aldehyde $(1 \mathrm{mmol})$, Ethyacetoacetate $(1 \mathrm{mmol})$, Malononitrile $(1.2 \mathrm{mmol})$, Hydrazine hydrate $(2 \mathrm{mmol})$, and $1 \mathrm{ml}$ of water in a flask fitted with a reflux condenser. The resulting mixture was heated to reflux (oil bath) with stirring for $20 \mathrm{~min}$. Then acetone $(2 \mathrm{ml})$ was added, and the mixture was stirred for $2 \mathrm{~min}$. Thereafter, the products and catalysts were isolated as described above and recrystallized from ethanol (96\%) to afford pyrano[2,3-c] pyrazole 5(a-e) (Figure 2). 

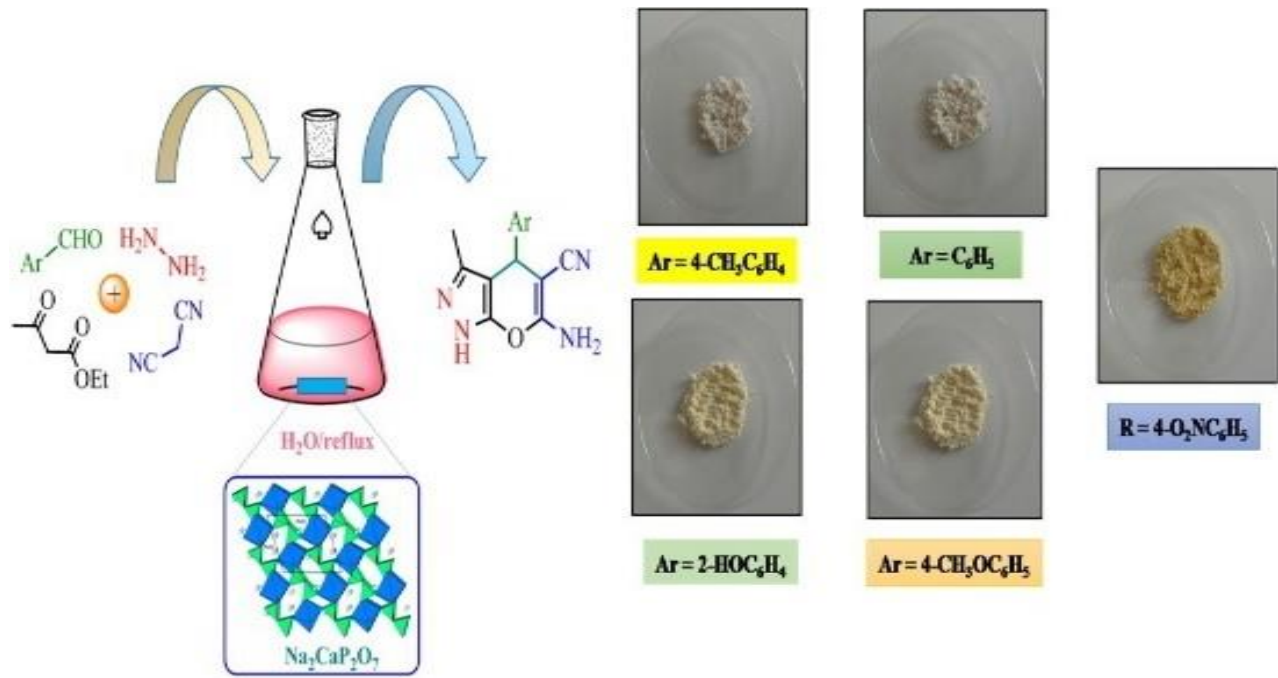

Figure 2. Proposed one-pot reaction of pyrano[2,3-c] pyrazoles 5(a-e) catalyzed by $\mathrm{Na}_{2} \mathrm{CaPO}_{7}$.

2.1.3. Characterization of the five selected compounds 5 (a-e).

6-Amino-3-methyl-4-phenyl-1,4-dihydropyrano[2,3-c]pyrazole-5-carbonitrile (5a) : White solid; m.p. $245-246{ }^{\circ} \mathrm{C}$ (lit. $\left.244-245^{\circ} \mathrm{C}\right)$; Rf (20\% AcOEt/hexane) 0.61; (HPLC): (tR = $3.63 \mathrm{~min}$ ); 1H NMR (300 MHz, DMSO-d6, ppm): $\delta 1.73$ (s, 3H), $4.54(\mathrm{~s}, 1 \mathrm{H}), 6.83(\mathrm{~s}, 2 \mathrm{H})$, 7.11-7.45 (m, 5H), $12.11(\mathrm{~s}, 1 \mathrm{H}) ; 13 \mathrm{C}$ NMR (75 MHz, DMSO-d6, ppm): $\delta 9.7$ (CH3), 36.2 (pyran C4), 57.2 (C5-CN), $97.6(\mathrm{C} 8), 120.7(\mathrm{CN}), 126.7,127.4,127.5,128.4,128.5,135.5$ (aromatic carbons), 144.4 (C3), 154.7 (C7), 160.8 (C6-NH2); IR (KBr, cm $\left.{ }^{-1}\right): 3473$ (NH2), $3170(\mathrm{NH}), 2191(\mathrm{CN}), 1649(\mathrm{C}=\mathrm{N}), 1604(\mathrm{Ar})[6]$.

6-Amino-3-methyl-4-(4-methylphenyl)-1,4-dihydropyrano[2,3-c]pyrazole-5-

carbonitrile 5b White solid; m.p. 205-207 ${ }^{\circ} \mathrm{C}$ (lit. 206-207 $\left.{ }^{\circ} \mathrm{C}\right)$; Rf (20\% AcOEt/hexane) 0.7; (HPLC): (tR = $3.53 \mathrm{~min}) ; 1 \mathrm{H} \mathrm{NMR} \mathrm{(300} \mathrm{MHz,} \mathrm{DMSO-d6,} \mathrm{ppm):} \delta 1.75$ (s, 3H, CH3), 2,22 (s, $3 \mathrm{H}, \mathrm{CH} 3), 4.51$ (s, 1H, C4-H), 6.81 (s, 2H, NH2), 7,03 (m, 4H, HAr), 12.06 (s, 1H, NH); 13C NMR (75 MHz, DMSO-d6, ppm): $\delta 9.7$ (CH3), 20.5 (CH3), 35.8 (pyran C4), 57.4 (C5-CN), 97.7 (C8), 120.7 (CN), 127.3-129.1, 136.7 (6 aromatic carbons), 141.4 (C3), 154.7 (C7), 160.7 (C6-NH2) ; IR (KBr, cm $\left.{ }^{-1}\right)$ : $3483(\mathrm{NH} 2), 3113(\mathrm{NH}), 2193(\mathrm{CN}), 1641(\mathrm{C}=\mathrm{N}), 1602$ (Ar) [6].

6-Amino-3-methyl-4-(2-hydroxyphenyl)-1,4-dihydropyrano[2,3-c]pyrazole-5-

carbonitrile 5c White solid; m.p. 215-218 ${ }^{\circ} \mathrm{C}$; $1 \mathrm{H}$ NMR (300 MHz, DMSO-d6, ppm): $\delta 1.9$ (s, $3 \mathrm{H}), 4.56(\mathrm{~s}, 1 \mathrm{H}), 6.70(2 \mathrm{H}), 6.94-7.18(\mathrm{~m}, 5 \mathrm{H}), 11.00(\mathrm{~s}, 1 \mathrm{H})$; 13C NMR (75 MHz, DMSOd6, ppm): $\delta 9.85,28.64,55.06,104.95,115.1,120.79,123.53,124,25,127.55,128.93,136.52$, 148.39, 159.09, 160,08; IR ( $\left.\mathrm{KBr}, \mathrm{cm}^{-1}\right): 3448,3419,3352,2189,1660,1610$ [6] .

6-Amino-3-methyl-4-(4-methoxyphenyl)-1,4-dihydropyrano[2,3-c]pyrazole-5-

carbonitrile 5d White solid; m.p. 210-212 ${ }^{\circ} \mathrm{C}$; $1 \mathrm{H}$ NMR (300 MHz, DMSO-d6, ppm): $\delta 1.78$ $(\mathrm{s}, 3 \mathrm{H}), 3.72(\mathrm{~s}, 3 \mathrm{H}), 4.54(\mathrm{~s}, 1 \mathrm{H}), 6.83(2 \mathrm{H}), 6.86-7.08(\mathrm{~m}, 4 \mathrm{H}), 12.09(\mathrm{~s}, 1 \mathrm{H}) ; 13 \mathrm{C}$ NMR $(75$ MHz, DMSO-d6, ppm): $\delta$ 9.66, 35.51, 55.00, 57.9, 97.89, 113.79, 120.69, 128.44, 135,64, 136.43, 154.77, 158.01, 160.68; IR (KBr, cm$\left.{ }^{-1}\right): 3483,3255,3113,2193,1643,1602$ [6].

6-Amino-3-methyl-4-(4-nitrophenyl)-1,4-dihydropyrano[2,3-c]pyrazole-5-carbonitrile 5e Wellow solid; m.p. $248-250{ }^{\circ} \mathrm{C}$ (lit. 248-249 ${ }^{\circ} \mathrm{C}$ ); Rf (20\% AcOEt/hexane) 0.64; (HPLC): $(\mathrm{tR}=3.56 \mathrm{~min}) ; 1 \mathrm{H}$ NMR $(300 \mathrm{MHz}, \mathrm{DMSO}-\mathrm{d} 6, \mathrm{ppm}): \delta 1.8(\mathrm{~s}, 3 \mathrm{H}, \mathrm{CH} 3), 4.51(\mathrm{~s}, 1 \mathrm{H}, \mathrm{C} 4-$ H), 7.05 (s, 2H, NH2), 7,46 (d, 2H, HAr), 8,21 (d, 2H, HAr), 12.20 (s, 1H, NH); 13C NMR (75 MHz, DMSO-d6, ppm): $\delta 9.6(\mathrm{CH} 3), 35.8$ (pyran C4), $55.9(\mathrm{C} 5-\mathrm{CN}), 96.5(\mathrm{C} 8), 120.4(\mathrm{CN})$, 123.8, 124.1, 128.8, 135.8 (5 aromatic carbons), 146.3 (C3), 152.0 (C7), 154.6 (CAr-NO2), 
161.1 (C6-NH2); IR (KBr, cm-1): 3477, $3228(\mathrm{NH} 2), 3118(\mathrm{NH}), 2196(\mathrm{CN}), 1651(\mathrm{C}=\mathrm{N})$, 1595 (Ar) [6] (See Figures S1-S16 of ESI part). .

\subsection{Microbiology.}

\subsubsection{Tested strains.}

Four bacterial strains, E. coli, S. aureus, K. pneumoniae, and L. monocytogenes have been used in this study. All strains were isolated, purified, and identified in the laboratory of physiopathology, molecular genetics, and Biotechnology at the Faculty of Sciences, Ain Chock, Casablanca.

\subsubsection{Bacterial growth.}

The media used for antibacterial screening was Lauria Broth (LB) and Brain Heart Infusion (BHI) medium. All used media were sterilized for $20 \mathrm{~min}$ at $120^{\circ} \mathrm{C}$. The fresh culture was prepared by inoculating a liquid medium tube $(5 \mathrm{ml})$ with $50 \mu \mathrm{l}$ of preculture and incubated overnight. Thereafter, the strains are used at a $108 \mathrm{CFU} / \mathrm{mL}$ concentration for agar diffusion technique and microdilution assays. Then the targeted strains are incubated at $37^{\circ} \mathrm{C}$ for $24 \mathrm{~h}$. All microbial assays were carried out in triplicate, and results were expressed as mean \pm SD.

\subsubsection{Preparation of stock solutions.}

To prepare a final concentration of $25 \mathrm{mg} / \mathrm{ml}$, we solubilized the selected compounds in DMSO. Then the stock solutions were stored in sterile containers in obscurity. The dilutions of molecules were prepared in a concentration range (from 0.390 to $25 \mathrm{mg} / \mathrm{ml}$ ), stored in the same condition as a stock solution until their use.

\subsubsection{Well diffusion method.}

The targeted compounds 5(a-e) were tested for their antibacterial activity against $E$. coli; S.aureus, K.pneumonia, and L.monocytogene by using the agar diffusion method as described by the National Committee for Clinical Laboratory Standards (NCCLS)[14]. The susceptibility of the bacterial strains to the tested compounds was determined by measuring the inhibition zone diameters (IZD) which are expressed in $\mathrm{mm}$. To access the antibacterial effect of these compounds, we subculture the different strains by streaking the supercooled media (LB and BHI) with bacterial inoculum adjusted to $10^{8} \mathrm{CFU}$ (bacteria/Ml) and then poured into Petri dishes. After solidification of the agar medium, wells of $5 \mathrm{~mm}$ were made on each plate. Under aseptic conditions, we injected separately $50 \mu \mathrm{l}$ of the tested molecule (Figure 3 ). Then the plates were incubated at $30-37^{\circ} \mathrm{C}$ for $24 \mathrm{~h}$. Thereafter, we measured the inhibition zone size, and the results were gathered in Table 2. We used as positive control some standard antibiotics (Chloramphenicol, rifampicin, penicillin G, Tetracycline; Novobiocine, and Ampiciline) and as negative control DMSO. All tests were performed for each strain and repeated in triplicate. 


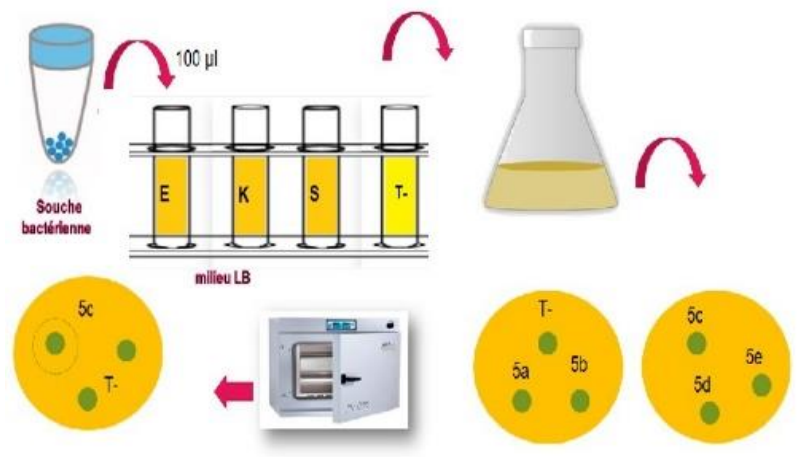

Figure 3. The agar diffusion method for the evaluation of pyrano[2,3-c] pyrazole activity.

\subsubsection{Antibacterial sensitivity test: Broth Microdilution.}

Antibacterial sensitivity test: Broth Microdilution. For initial screening, $100 \mu \mathrm{L}$ of antibacterial drugs (designated as (5a-e)), and $20 \mu \mathrm{L}$ of bacterial suspension with a final concentration of $1 \times 10^{8} \mathrm{CFU}$ (strains/Ml) were injected separately in each well that contained the BHI medium $(100 \mu \mathrm{L})$ previously. A Positives and negatives control was also prepared (see Figure 4). Then microplates were incubated at $37^{\circ} \mathrm{C}$ for $18-24$ hours. After incubation time, the determination of MIC was based on visual growth (turbidity), which was revealed by supplementation with $10 \mu \mathrm{L}$ of resazurin $(0.01 \%)$ and then the microplate of 96 -wells incubated at $37{ }^{\circ} \mathrm{C}$ for $2 \mathrm{~h}$. The MIC values reflected the minimal inhibitory concentration of the selected compounds at which no change in resazurin staining (from pink to purple) has occurred[9]. The obtained results were expressed as an average of at least three independent assays.

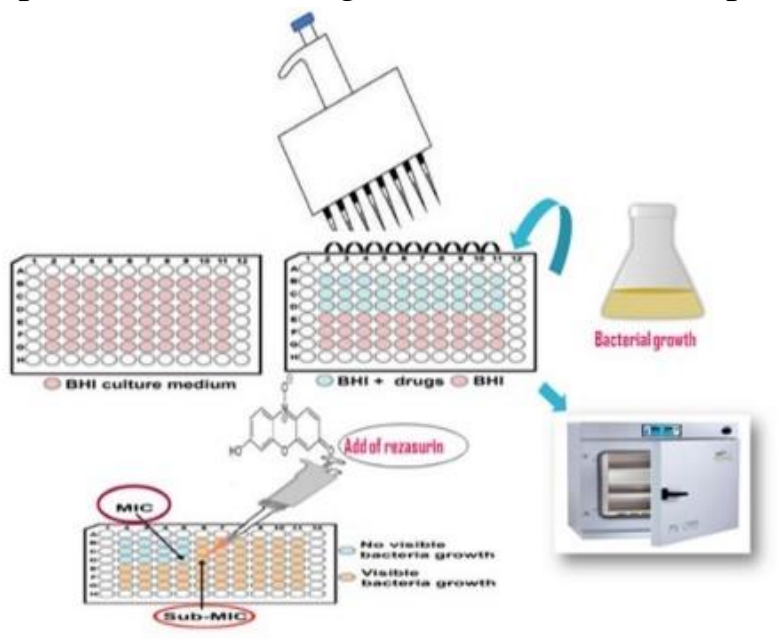

Figure 4. The microdilution method for pyrano[2,3-c] pyrazole screening.

\subsection{Studies in silico.}

\subsubsection{In-Silico predictive studies: ADME/Tox.}

Drug-likeness plays a key role in the prediction of drug-like properties. It is defined as guidelines for the structural properties of compounds, used for fast prediction of drug absorption and drug-like properties of molecules to confirm their ability to be used as a drug candidate. The selected compounds $\mathbf{5}(\mathbf{a}-\mathbf{e})$ were appraised based on the various pharmacokinetic rules including Veber, and Lipinski rules (absorption, distribution, metabolism, excretion, and toxicity) accompanying ADMET parameters scores using two 
freely accessible web server "Swiss ADME" (http://swissadme.ch/index.php\#undefined) and "PreADMET ver 2.0" (https://preadmet.bmdrc.kr/) [10].

\subsubsection{Docking studies.}

\subsubsection{Preparation of target.}

The proteins used were the following(table 1 and figure 5): The X-ray crystal data of target enzyme MurB (PDB id: 1MBT) and DNA gyrase(PDB ID 3G7B ) was retrieved from Protein Data Bank (RCSB) (http://www.rcsb.org/pdb)[7,15-17]. Published structures were edited to remove water and heteroatoms using Discovery Studio Visualizer.

Table 1. The data of the respective protein target have been extracted from the PDB.

\begin{tabular}{l|l|l} 
Target & Class & PDB(ID) \\
\hline MurB & $\mathrm{A}^{1}$ & 1MBT \\
\hline DNA Gyrase & $\mathrm{B}^{2}$ & $3 \mathrm{G} 7 \mathrm{~B}$ \\
${ }^{1}$ Inhibitor of cell wall synthesis; ${ }^{2}$ Inhibitor of nucleic acid.
\end{tabular}

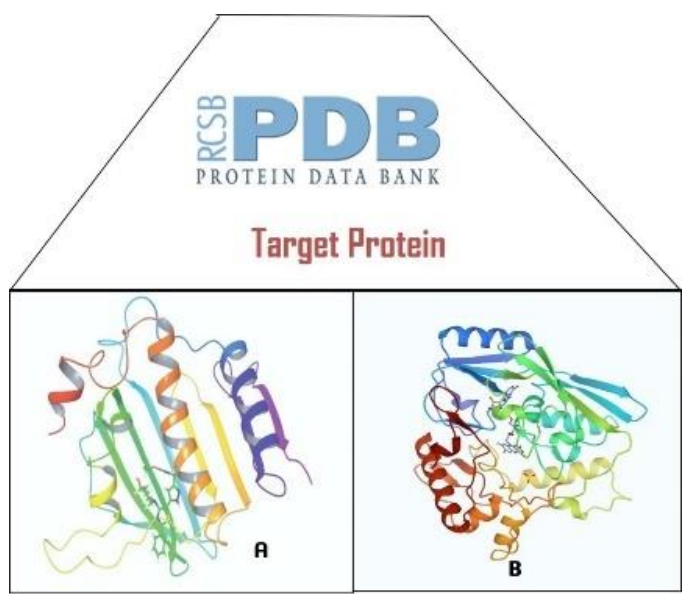

Figure 5. Enzyme MurB(A) and Protein Gyrase B(B) were downloaded from the Protein data bank.

\subsubsection{Preparation of ligand structures.}

The SDF files of the synthesized compounds were retrieved from NCBI PubChem and saved in PDB extension [15]. The 3D structures of the selected ligands from Pub chem NCBI are represented in Figure 6.

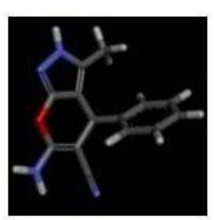

5a

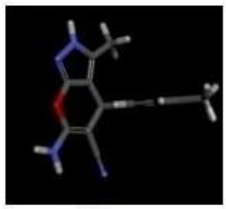

$5 b$

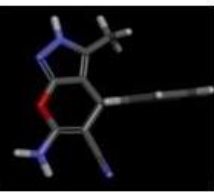

5d

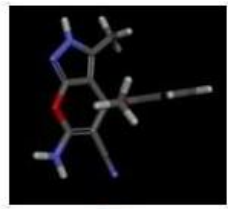

$5 c$

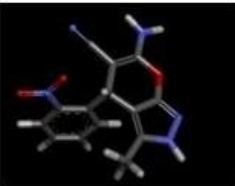

$5 e$

Figure 6. The three-dimensional structure of the selected ligand is visualized by Biova Discovery Studio Visualizer [15]. 
2.4.2.3. Protein-Ligand Docking studies.

We stimulated the docking interaction by using the software AutoDock 1.5.6 (MGL tools- 1.5.6). Polar hydrogen atoms and Kollman united charges were added to all target proteins, and the resulting file has been saved in the pdbqt extension[15]. For the docking calculation, a grid box of $60 \times 60 \times 60 \AA$ in $x, y, z$ directions was created to cover the active site of the target $[5,18,19]$. The default grid points spacing was fixed to $0.375 \AA$ and centred at $\mathrm{x}=$ 42.527, $y=-46.679, z=65.559$. We used the Lamarckian Genetic Algorithm (LGA) [19]for flexible docking calculations in this work. The LGA parameters included size, energy screening, mutation rate, and crossover rate. After the calculation procedure, we selected the best conformations of the complex from the 10 calculated based on their binding energy scores. Then the complex interaction map was displayed using Discovery Studio Visualizer.

\section{Results and Discussion}

\subsection{Antibacterial test.}

\subsubsection{Agar diffusion method.}

The antibacterial effect of the five synthesized compounds against the four strains was investigated using the diffusion method, and the results are reported in Table 2.

Table 2. The inhibition of bacterial growth after treatment with the synthesized pyrano[2,3-c] pyrazole 5(a-e).

\begin{tabular}{|c|c|c|c|c|}
\hline \multirow{3}{*}{ Compounds } & \multicolumn{4}{|c|}{ Zone of inhibition (in $\mathrm{mm}$ ) at concentration $25 \mathrm{mg} / \mathrm{mL}$ after $24 \mathrm{~h}$} \\
\hline & \multicolumn{4}{|c|}{ Bacterial strains } \\
\hline & E. coli & K. pneumonia & S. aureus & L.monocytogene \\
\hline $5 \mathrm{a}$ & $10 \mathrm{~mm} \pm 0.045$ & $10 \mathrm{~mm} \pm 0.03$ & $8 \mathrm{~mm} \pm 0.03$ & $10 \mathrm{~mm} \pm 0.03$ \\
\hline $5 b$ & $10 \mathrm{~mm} \pm 0.04$ & $11 \mathrm{~mm} \pm 0.05$ & $10 \mathrm{~mm} \pm 0.04$ & $11 \mathrm{~mm} \pm 0.03$ \\
\hline $5 \mathrm{c}$ & $12 \mathrm{~mm} \pm 0.05$ & $13 \mathrm{~mm} \pm 0.04$ & $12 \mathrm{~mm} \pm 0.04$ & $13 \mathrm{~mm} \pm 0.05$ \\
\hline $5 \mathrm{~d}$ & $8 \mathrm{~mm} \pm 0.03$ & NA & NA & NA \\
\hline $5 \mathrm{e}$ & NA1 & $13 \mathrm{~mm} \pm 0.03$ & NA & NA \\
\hline Tera & $20 \mathrm{~mm} \pm 0.05$ & $7 \mathrm{~mm} \pm 0.05$ & $10 \mathrm{~mm} \pm 0.05$ & $22 \mathrm{~mm} \pm 0.05$ \\
\hline Rif & $7 \mathrm{~mm} \pm 0.05$ & $15 \mathrm{~mm} \pm 0.05$ & $15 \mathrm{~mm} \pm 0.05$ & $8 \mathrm{~mm} \pm 0.05$ \\
\hline Vanc & $6 \mathrm{~mm} \pm 0.05$ & NA & NA & NA \\
\hline Amp & NA & NA & NA & NA \\
\hline
\end{tabular}

Values were means of three experiments \pm SD.

${ }^{1}$ NA: No activity of the selected compounds on the inhibition of the growth of the strain. Rif: Rifampicin, Tetr: Tetracycline, Amp: Ampicillin, and Vanc: Vancomycin.

According to the tabulated statistics, all studied compounds exhibited excellent to poor activity against the different strains (Table 2). Interestingly, we noticed that the $\underline{\mathbf{5 c}}$ derivative afforded outstanding inhibition potential against the selected bacteria. At the $25 \mathrm{mg} / \mathrm{mL}$ concentration, we obtained an IZD (inhibition zone diameter) of $13 \mathrm{~mm}$. Indeed, the antimicrobial susceptibility testing results of the selected compound $\underline{\mathbf{5 c}}$ compared to a panel of control antibiotics were also gathered in Table 2. Among the antibiotics used, chloramphenicol gave the best inhibition result. For novobiocin, penicillin G, Ampicillin, and vancomycin, no

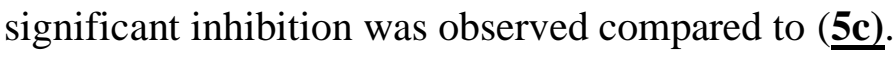

\subsubsection{MIC screening.}

The foregoing results prompt us to evaluate the sensitivity of the studied strains toward the targeted derivatives. Minimum inhibitory concentration (MIC) results of the most active compounds were projected in Figures 6 and 7. All synthesized compound 5a-e was found to 
display noticeable antimicrobial behavior against the tested microorganisms. The MIC value reported herein demonstrated that the studied strains are sensitive to these derivatives, especially the $\underline{\mathbf{5 c}}$ that showed the most significant activity against $E$. coli and $K$. pneumonia (MIC is $6.25 \mathrm{mg} / \mathrm{mL}$ ). Besides that, this product is also active on L. monocytogenes and $S$. aureus strain at $12.5 \mathrm{mg} / \mathrm{mL}$ concentrations. On the other side, the $\mathbf{5 a}, \mathbf{5 b}, \mathbf{5 d}$, and $\mathbf{5 e}$ products own their top activity against $E$. coli and $K$. pneumonia $(\mathrm{MIC}=12.5 \mathrm{mg} / \mathrm{mL}$ ). We also noticed that $S$. aureus is more sensible to $\underline{\mathbf{5 d}}$ and $\underline{\mathbf{5} \mathbf{e}}$ (the MIC has recorded $12.5 \mathrm{mg} / \mathrm{mL}$ ) than $\underline{\mathbf{5 a}}$ and $\underline{\mathbf{5 b}}$ (Figure 7 and Figure S 21).

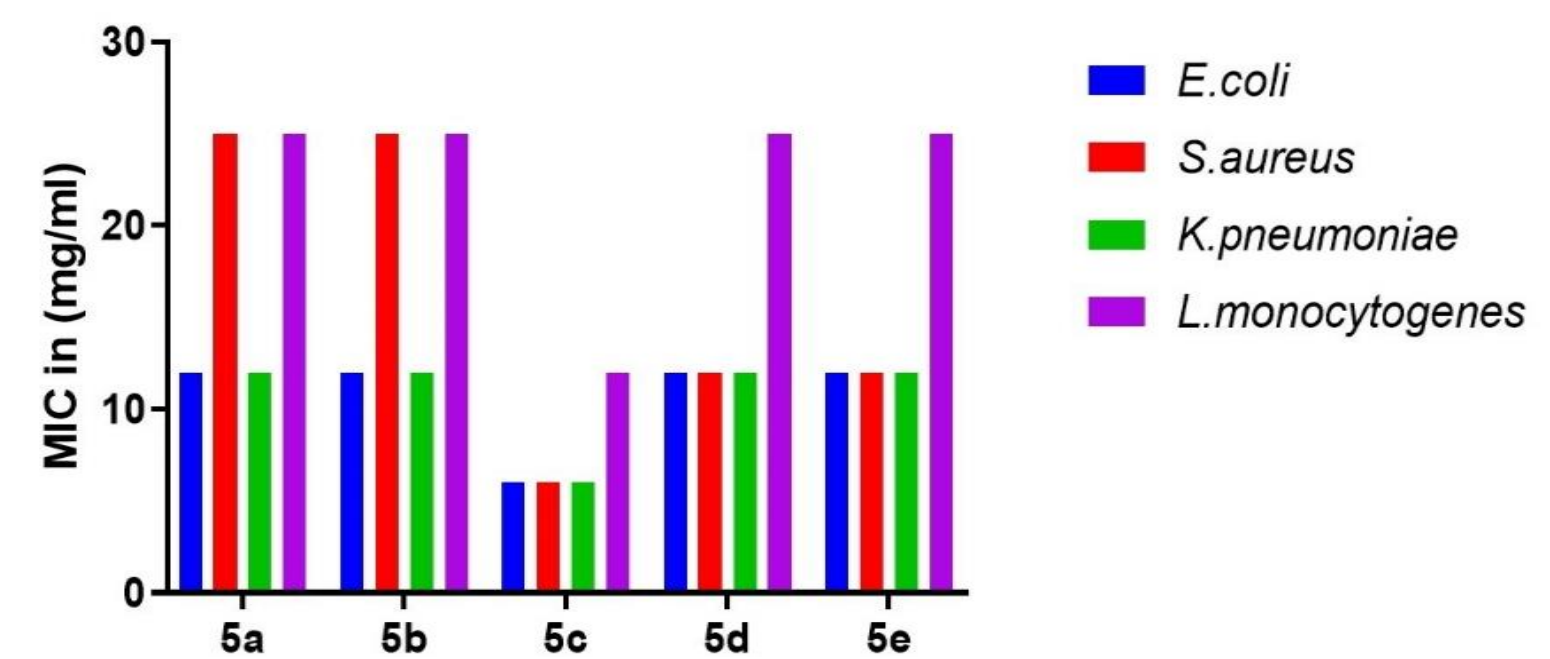

Figure 7. Minimum inhibitory concentration (MIC) of the selected compounds against four multidrug-resistant bacteria.

\subsection{Virtual screening of the studied compounds.}

\subsubsection{Prediction of Toxicity.}

Considering the importance of predicting toxicity in drug design, two computer interfaces have been used in the current study: SwissADME and preADMET. This software predicts the probability of carcinogenicity and mutagenicity in various organisms using in silico models. The toxicity analysis also provides information on the lipophilicity of the ligands, which is predicted by the MIlog P parameter, the hydrogen bonding potential of the compounds, and their molecular flexibility[19,20]. The different drug-likeness proprieties for all selected compounds were in harmony with Lipinski's rule of five[17] and were considered safe for biological experiments. The results of the prediction are presented in Tables S3 and S4(Supplementary Files)

3.2.2. Docking studies and scoring of the synthesized pyrano[2,3-c] pyrazoles.

\subsubsection{Calculation of binding energy.}

Modeling studies are essential to find an exact image for the mechanisms of action of these designed compounds. Our Docking investigation has been performed by using AutoDock tools software. The lowest free energies of binding $(\Delta \mathrm{G})$ are observed with the compounds $\mathbf{5 b}$ and $\mathbf{5 c}$, which confirmed the good affinity between the protein and ligand in contrast to the ligand of reference (ciprofloxacin). 
Table 3. Representing the binding affinity $(\mathrm{kcal} / \mathrm{mol})$ and details of $\mathrm{H}$-bond interactions of the best performing pyrano[2,3-c] pyrazole derivatives with DNA gyrase B and MurB.

\begin{tabular}{|c|c|c|c|}
\hline Ligand & Score $(\mathrm{kcal} / \mathrm{mol})$ & Résidu & Liaison $\mathbf{H}$ \\
\hline \multicolumn{4}{|c|}{ Enzyme MurB of E. coli } \\
\hline $5 \mathrm{a}$ & -6.73 & ILE59 Asn178 Tyr179 Leu57 Val181 Arg207 & 2 \\
\hline $5 b$ & -7.05 & Tyr179 Val181 ILE59 & 1 \\
\hline $5 \mathrm{c}$ & -6.73 & Val181 Tyr179 Arg207 Gly135 & 3 \\
\hline $5 \mathrm{~d}$ & -6.64 & Val181 Tyr179 ILE59 ILE174 Gly161 Ser220 Ser64 & 3 \\
\hline $5 e$ & -7.63 & Gly 161 Gly 163 Gly127 ARG207 Ser64 & 5 \\
\hline $\mathrm{CPF}$ & -7.62 & SER 64 ASN 62 TYR179 Ser125 Gly63 & 4 \\
\hline \multicolumn{4}{|c|}{ DNA gyrase B of S. aureus } \\
\hline $5 \mathrm{a}$ & -4.36 & $\begin{array}{l}\text { Thr } 171 \\
\text { Glu } 50\end{array}$ & 1 \\
\hline $5 b$ & -5.46 & $\begin{array}{l}\text { Asp } 81 \\
\text { Lys78 }\end{array}$ & 1 \\
\hline $5 \mathrm{c}$ & -5.45 & $\begin{array}{l}\text { Glu } 68 \\
\text { Lys } 170 \\
\text { Gln66 }\end{array}$ & 3 \\
\hline $5 d$ & -4.07 & Lys78, Glu 72, Asp81 Thr80 Glu68 & 2 \\
\hline $5 e$ & -4.95 & Ile102 Val 130 Glu 68 Lys 78 & 2 \\
\hline
\end{tabular}

\subsubsection{Interaction with the enzyme MurB.}

The selected compounds 5 (a-e) interacted with Mur B of $E$. coli via several residues (see table 3 ). Compound $\underline{5}$ e takes the first position with a high binding energy of -7.63 , which is similar to the score of ciprofloxacin. This derivative forms hydrogen bonds within the active site of the enzyme MurB. Additionally, $\underline{5 b}$ is considered a good inhibitor due to their high binding energy of -7.05 and the tight interaction formed with residues observed in the enzyme's active pocket, including SER 64, ASN 62, TYR179 Ser125 Gly63 (table 3). Also, the 5c and 5 a derivatives bind efficiently to the enzyme of $E$. coli with a binding energy of -6.75 through the formation of a complex stabilized with a hydrogen bond. For the $(\underline{5 c})$, the residues implicated in the interaction are Val181, Tyr179, Arg207, Gly135, Nevertheless the 5a formed a tight interaction with the ILE59, Asn178 Tyr179 Leu57 Val181 Arg207(see figure 8).

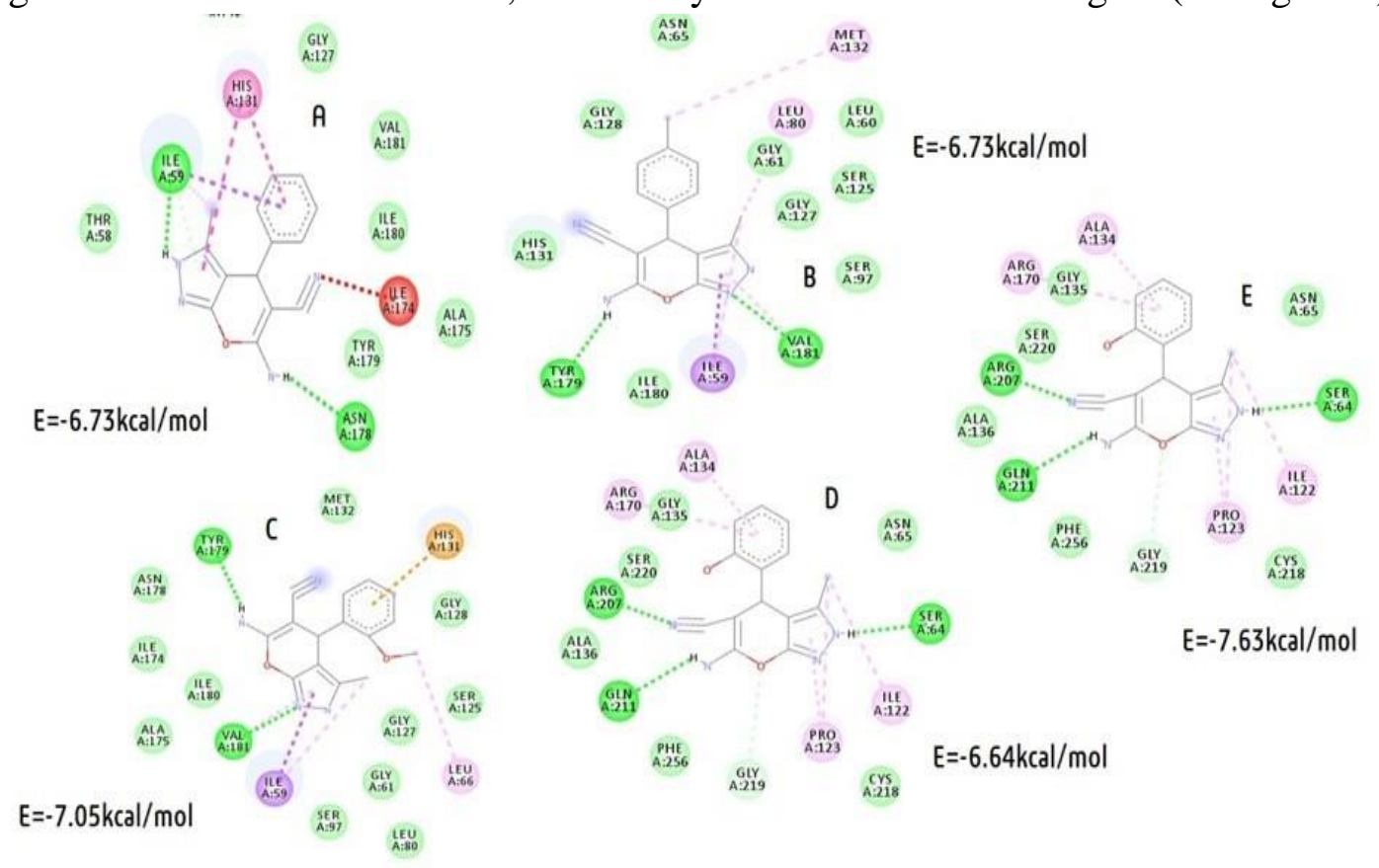

Figure 8. Representation of the 2D interaction between the tested compounds and the main MurB enzyme of $E$. coli. 


\subsubsection{Interaction with DNA gyrase B.}

A very similar value of binding free energy $(\sim-5.46 \mathrm{kcal} / \mathrm{mol})$ was found for compounds $\underline{5 b}, \underline{5 c}$, and ciprofloxacin against topoisomerase II DNA gyrase. In all investigated systems, we found H-bond interactions (Figure 9) involving the bases of DNA and the ligand. Compounds $\underline{5 \mathrm{~b}}$ and $\underline{5 \mathrm{c}}$ displayed a higher number of hydrogen bond interactions. In addition, the free binding energy of $-4.95 \mathrm{kcal} / \mathrm{mol}$ (Table 3 ) was found for compound ( $\underline{5 \mathrm{e}})$. However, the lowest value was for compound $\underline{5 \mathrm{~d}}(-4.07 \mathrm{kcal} / \mathrm{mol})$. The observed trend in the binding free energy was found to be consistent with the experimental inhibition trend for the molecules.

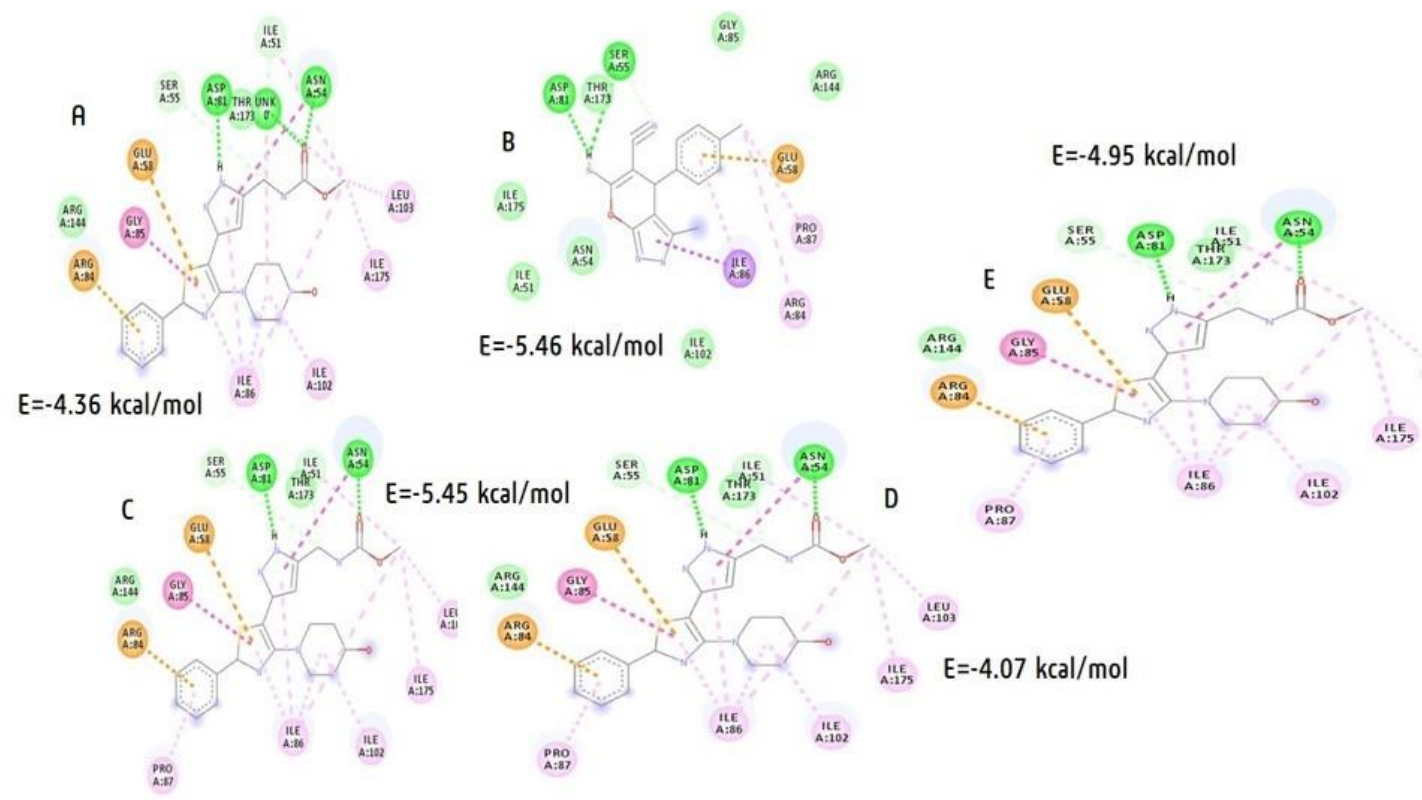

Figure 9. Schematic representation of the complex pyrano[2,3-c] pyrazoles -DNA gyrase and their energy values.

\section{Discussion}

Innovative therapeutic pyrano[2,3-c] pyrazoles were successfully prepared by using the eco-friendly synthetic route via the multicomponent reaction[21-24]. Then the selected compounds are tested for their antimicrobial effectiveness against four microbial strains. The antibacterial effects of the compounds that produced a zone of inhibition were further tested quantitatively by the broth microdilution method to determine MIC value (the lowest concentration of the compound inhibiting the growth of the tested bacteria).

The sensitivity of the studied strains against the selected derivatives provides their antibacterial behavior estimated by measuring the inhibition zone formed and using the value of $\mathrm{MIC} \pm \mathrm{SD}$. By analyzing the obtained results, we can classify these products as follows: the $5 \mathrm{c}$ compound takes the place position due to their great effect against the four multiresistant strains viz, $S$. aureus, E. coli et $L$. monocytogenes, and especially $K$. pneumonia $(5 \mathrm{c}>5 \mathrm{e}>5 \mathrm{~d}$ $>5 \mathrm{~b}>5 \mathrm{a})$.

While the four other compounds possessed variable antibacterial activity as a function of the strain used and the nature of the substituted derivatives, for example, the $5 \mathrm{~d}$ and $5 \mathrm{e}$ derivatives are more active against gram-positive strains ( $S$. aureus). Nevertheless, the 5a and $5 \mathrm{~b}$ derivatives are more efficient against gram-negative strains ( $K$. pneumonia). It's gratifying to elucidate that this antibacterial sensitivity is presumably related to the structure of the tested 
compounds; as described previously, the substitution of bioactive motives methyl; hydroxyl, and methoxy in the phenyl ring enhance this activity[25]; accordingly, when the aromatic aldehyde is replaced with hydroxyl scaffold, we notice a slight and inconspicuous antibacterial activity $(5 \mathrm{c})$. Therefore, the activity of molecules can also be explained by the nature of the strain; for example, the synthesized compounds can inhibit the growth of gram-negative bacteria (viz K.pneumonaie), which confirmed their potential against these resistant strains characterized by their surface membrane wall that performance as a fence or selective barrier to the penetration of substances soluble and various elements, including antibacterial agents[18,26].

Our results are in harmony with some previous studies published in 2019[27] that showed clearly the excellent antibacterial behavior of the pyrano[2,3-c] pyrazole derivative, especially against $S$. aureus with a zone of inhibition $\geq 8 \mathrm{~mm}$ and MIC of $64 \mathrm{mg} / \mathrm{mL}$. Another research work achieved in 2008 [28] also confirmed the prominent antibacterial activity of some pyrano[2,3-c] pyrazole (6d $6 \mathrm{f}$ and $6 \mathrm{~g}$ ) against a panel of gram-positive and negative strains ( S.aureus B.subtilis and E.coli) with a significative MIC varied between 12.5$50 \mathrm{mg} / \mathrm{mL}$.

On the other side, molecular docking was used to investigate and support the experimental data through the binding mode interaction between the selected compounds and receptors at binding sites. MurB enzyme of E. coli is essential for the formation of muramyl sugar [29] which is essential for peptidoglycan biosynthesis, and DNA gyrase B is important for the supercoiling of DNA during replication and plays a vital role in the growth of S.aureus. Docking analysis of the five pyranopyrazoles derivatives, compared to the drug ciprofloxacin, revealed important interactions between these derivatives and enzymes.

For Mur B, the selected compounds established H-bonds with one or more amino acids in the target active pocket. We observed an interaction of compound ( $\underline{5 \mathrm{e}}$ ) with Gly 161, Gly 163, Gly127, ARG207, Ser64, whereas compound (드) constructed a tight interaction with Val181, Tyr179 Arg207 Gly135. These amino acids reside at the active site of the enzyme, are crucial in the biosynthesis of peptidoglycan. Any modification in these amino acids could downregulate the enzyme activity, which induces bacterial cell death[29]. However, the docking studies with the pyrazole derivatives showed that our derivatives established a tight interaction with the target DNA gyrase B of S. aureus. Through Molecular docking and dynamics studies, it was clear that among the five derivatives, the compounds $5 \mathrm{c}, 5 \mathrm{~b}$, and $5 \mathrm{e}$ are the most active compounds and can present very interesting in vitro antimicrobial activities.

These compounds could be considered as a valuable tool for the design and development of new effective compounds. Our docking studies have been performed on two important targets to elucidate the mechanism of action for these compounds. Both Mur B of $E$. coli and topoisomerase II DNA gyrase from $S$. aureus were studied as potential targets[11,3032]. The observed inhibitory activity and the in silico molecular docking were correlated scores of the best compounds 5b, 5c, and 5e was obtained. Moreover, these compounds also exhibited drug-likeness properties, leading us to consider them as a potential scaffold for improving antibacterial activity.

From the current biological funding and those of the literature, we confirmed the outstanding activity of this motif, which oriented us to use the green synthetic approach as a great attempt to formulate new biologically active compounds. As a consequence, there is a high necessity for additional preclinical examination to discover novel, innovative drugs or adjuvants more efficient and able to control the emergence of NIs disease 


\section{Conclusions}

The current study reported in silico design, synthesis, and evaluation of the antibacterial activity of five pyrano[2,3-c] pyrazole 5(a-e) derivatives. As expected, pyrano[2,3-c] pyrazole has superior antibacterial activity than standard antibiotics. Our finding revealed that the selected compounds act as potential antibacterial agents against four human pathogenic bacteria: E. coli, S. aureus, L. monocytogenes, and K. pneumoniae. Careful investigation in this series gave the molecule 5c the most promising inhibitor of DNA-gyrase and MurB based on the calculations of score energies, drug-likeness predictions, and antibacterial screening.

\section{Funding}

The current research was done in the context of university research and benefits from the general funding given to the PGMB laboratory.

\section{Acknowledgments}

The authors express their thanks to the team of the analytical Center at the Faculty of Sciences Ain Chock, where we performed the infrared spectra studies.

\section{Conflicts of Interest}

All authors declared that there is no conflict of interest regarding the publication of this paper.

\section{References}

1. Addoum, B.; El Khalfi, B.; Idiken, M.; Sakoui, S.; Derdak, R.; Filali, O. A.; Elmakssoudi, A.; \& Soukri, A. Synthesis, Characterization of Pyrano-[2,3-c]-Pyrazoles Derivatives and Determination of Their Antioxidant Activities. Iranian Journal of Toxicology 2021, 15, http://dx.doi.org/10.32598/ijt.15.3.798.

2. Patil, R.; Chikhale, R.; Khanal, P.; Gurav, N.; Ayyanar, M.; Sinha, S.; Prasad, S.; Nandan, Y.; \& Wanjari, M.. Computational and network pharmacology analysis of bioflavonoids as possible natural antiviral compounds in COVID-19. Informatics in Medicine Unlocked 2021, 22, 100504, https://doi.org/10.1016/j.imu.2020.100504.

3. El-assaly, S.A.; Ismail, A.E.A.; Abdel, H.; \& Mohamed, G.. Synthesis, molecular docking studies , and antimicrobial evaluation of pyrano [ 2 , 3- c ] pyrazole derivatives. Current Chemistry Letters 2021, 10, 309328, https://doi.org/10.5267/j.ccl.2021.3.003.

4. Fahim, A.M.; Farag, A.M. Synthesis, antimicrobial evaluation, molecular docking and theoretical calculations of novel pyrazolo [ 1 , 5- a ] pyrimidine derivatives. Journal of Molecular Structure 2020, 1199, 127025, https://doi.org/10.1016/j.molstruc.2019.127025.

5. Ansari, A.; Ali, A.; Asif, M. Review : Biologically active pyrazole derivatives Review : biologically active pyrazole derivatives. New J. Chem 2017, 16, 15-41, https://doi.org/10.1039/C6NJ03181A.

6. Arokiyaraj, S.; Bharanidharan, R.;Agastian, P.; Shin, H. Chemical composition, antioxidant activity and antibacterial mechanism of action from Marsilea minuta leaf hexane: Methanol extract. Chemistry Central Journal 2018, 12, 1-11, https://doi.org/10.1186/s13065-018-0476-4.

7. Belhani, B.; Berredjem, M.; Le Borgne, M.; Bouaziz, Z.; Lebreton, J.; Aouf, N.E.A. one-pot three-component synthesis of novel $\alpha$-sulfamidophosphonates under ultrasound irradiation and catalyst-free conditions. RSC Advances 2015, 5, 39324-39329, https://doi.org/10.1039/c5ra03473f.

8. da Silva, F.M.A.; da Silva, K.P.A.; de Oliveira, L.P.M.; Costa, E.V.; Koolen, H.H.F.; Pinheiro, M.L.B.; de Souza, A.Q.L.; de Souza, A.D.L. Flavonoid glycosides and their putative human metabolites as potential inhibitors of the sars-cov-2 main protease (Mpro) and rna-dependent rna polymerase (rdrp). Memorias Do Instituto Oswaldo Cruz 2020, 115, 1-8, https://doi.org/10.1590/0074-02760200207.

9. Sikandar, S.; Zahoor, A.F. Synthesis of Pyrano[2,3-c]Pyrazoles: A Review. Journal of Heterocyclic Chemistry 2021, 58, https://doi.org/10.1002/jhet.4191. 
10. Datar, P.A.; Jadhav, S.R. Design and Synthesis of Pyrazole-3-one Derivatives as Hypoglycaemic Agents. International Journal of Medicinal Chemistry 2015, 1-10, https://doi.org/10.1155/2015/670181.

11. El-Gazzar, A.R.B.A.; El-Enany, M.M.; Mahmoud, M.N. Synthesis, analgesic, anti-inflammatory, and antimicrobial activity of some novel pyrimido[4,5-b]quinolin-4-ones. Bioorganic and Medicinal Chemistry 2008, 16, 3261-3273, https://doi.org/10.1016/j.bmc.2007.12.012.

12. Hervin, V.; Arora, R.; Rani, J.; Ramchandran, S.; Bajpai, U.; Agrofoglio, L.A.; Roy, V. Mycobacterium tuberculosis Mur Ligases. Molecules 2020, 25, 1-21, https://doi.org/10.3390/molecules25214953.

13. Munir, M.T.; Eveillard, M., Irle, M.; Aviat, F.; Dubreil, L.; Federighi, M.; Belloncle, C. Testing the Antimicrobial Characteristics of Wood Materials: A Review of Methods. Antibiotics 2020, 9, 12-16, https://doi.org/10.3390/antibiotics9050225.

14. Dwivedi, K.D.; Borah, B.; Chowhan, L.R.; Approach, G.C. Ligand Free One-Pot Synthesis of Pyrano [ 2 , 3c ] pyrazoles in Water Extract of Banana Peel : A Green Chemistry Approach. Fronteirs in Chemistry 2020 , 7, 1-8, https://doi.org/10.3389/fchem.2019.00944.

15. Jagadeesan, C.S.G.; Vijayakuma, V.; Suresh, G.; Kris, G.; Jagadeesan, G.; Vijayakuma, V.; Palayam, M.; Suresh, G.; Krishnaswamy, G.; Aravindhan, S.; Günther, H. Pyrazole Based Inhibitors against Enzymes of Staphylococcus aureus: A Pyrazole Based Inhibitors against Enzymes of Staphylococcus aureus: A Computational Stuzy, Proteomics \& Bioinformatics 2018, 1-8, https://doi.org/10.4172/jpb.1000362.

16. Jouimyi, M.R.; Bounder, G.; Essaidi, I.; Boura, H.; Zerouali, K.; Lebrazi, H.; Kettani, A.; Maachi, F. Molecular docking of a set of flavonoid compounds with helicobacter pylori virulence factors CagA and VacA. Journal of HerbMed Pharmacology 2020, 9, 412-419, https://doi.org/10.34172/jhp.2020.52.

17. Kraicheva, I.; Bogomilova, A.; Tsacheva, I.; Momekov, G.; Troev, K. Synthesis, NMR characterization and in vitro antitumor evaluation of new aminophosphonic acid diesters. European Journal of Medicinal Chemistry 2009, 44, 3363-3367, https://doi.org/10.1016/j.ejmech.2009.03.017.

18. El-Deen, E.M.M.; Abd El-Meguid, E.A.A.; Karam, E.A.A.; Nossier, E.S.S.; Ahmed, M.F.F. Synthesis and biological evaluation of new pyridothienopyrimidine derivatives as antibacterial agents and Escherichia coli topoisomerase II inhibitors. Antibiotics 2020, 9, 1-19, https://doi.org/10.3390/antibiotics9100695.

19. Maddila, S.; Gorle, S.; Shabalala, S.; Oyetade, O.; Narayana, S.; Lavanya, P.; Jonnalagadda, S.B. Ultrasound mediated green synthesis of pyrano [ 2, 3-c ] pyrazoles by using Mn doped ZrO 2. Arabian Journal of Chemistry 2019, 12, 671-679, https://doi.org/10.1016/j.arabjc.2016.04.016.

20. Maleki, B.; Nasiri, N.; Tayebee, R.; Khojastehnezhad, A.; Akhlaghi, H.A. Green synthesis of tetrahydrobenzo[b] pyrans, pyrano[2,3-c] pyrazoles and spiro[indoline-3,4'-pyrano[2,3-c] pyrazoles catalyzed by nano-structured diphosphate in water. RSC Advances 2016, 6, 79128-79134, https://doi.org/10.1039/c6ra15800e.

21. Mallikarjuna, G.; Raul, J.; Hanuman, V.; Krishna, A.; Zyryanov, G.V.; Yuvaraja, G. An efficient and green approach: One pot, multi component, reusable catalyzed synthesis of pyranopyrazoles and investigation of biological assays. Journal of Saudi Chemical Society 2019, 23, 263-273, https://doi.org/10.1016/j.jscs.2018.07.003.

22. Naceiri Mrabti, N.; Dguigui, K.; Hadni, H.; Elhallaoui, M. QSAR study and molecular docking of benzimidazole derivatives inhibitors of p38 kinase. Moroccan Journal of Chemistry 2018, 6, 511-524, https://doi.org/10.48317/IMIST.PRSM/morjchem-v6i3.9273.

23. Boittier, E.D.; Tang, Y.Y.; Buckley, M.E.; Schuurs, Z.P.; Richard, D.J.; Gandhi, N.S. Assessing Molecular Docking Tools to Guide Targeted Drug Discovery of CD38 Inhibitors. International Journal of Molecular Sciences 2020 , 21, 1-19, https://doi.org/10.3390/ijms21155183.

24. Pore, D.M.; Patil, P.B.; Gaikwad, D.S.; Hegade, P.G.; Patil, J.D.; Undale, K.A. Green access to novel spiro pyranopyrazole derivatives. Tetrahedron Letters 2013, 54, 5876-5878, https://doi.org/10.1016/j.tetlet.2013.08.084.

25. Rakesh, K.P.; Vivek, H.K.; Manukumar, H.M.; Shantharam, C.S.; Bukhari, S.N.A.; Qin, H.; Sridhara, M.B. Promising bactericidal approach of dihydrazone analogues against bio- fi $\mathrm{lm}$ forming Gram-negative bacteria and molecular mechanistic studies. RSC Advances 2018, https://doi.org/10.1039/c7ra13661g.

26. Rauhamäki, S.; Postila, P.A.; Niinivehmas, S.; Kortet, S.; Schildt, E.; Pasanen, M.; Manivannan, E.; Ahinko, M.; Koskimies, P.; Nyberg, N.; Huuskonen, P.; Multamäki, E.; Pasanen, M.; Juvonen, R.O.; Raunio, H.; Huuskonen, J.; Pentikäinen, O.T. Structure-activity relationship analysis of 3-phenylcoumarin-based monoamine oxidase B inhibitors. Frontiers in Chemistry 2018, 6, 3-18, https://doi.org/10.3389/fchem.2018.00041. 
27. Tafti, A.D. ; Bi, B.; Mirjalili, F.; Bamoniri, A.; Salehi, N. Rapid four - component synthesis of dihydropyrano [ 2 , 3 - c ] pyrazoles using nano - eggshell / Ti ( IV ) as a highly compatible natural based catalyst. BMC Chemistry 2021, 15, 1-8, https://doi.org/10.1186/s13065-021-00734-5.

28. Velmurugan, K.; Don, D.; Kannan, R.; Selvaraj, C.; Vishnupriya, S.; Selvaraj, G.; Singh, S.K.; Nandhakumar, R. Heliyon Synthesis, antibacterial, anti-oxidant and molecular docking studies of imidazoquinolines. Heliyon 2021, 7, 1-11, https://doi.org/10.1016/j.heliyon.2021.e07484.

29. Cascioferro, A.S.; Carbone, D.; Parrino, B.; Giovannetti, E.; Cirrincione, G. Therapeutic strategies to counteract antibiotic resistance in MRSA biofilm-associated infections. ChemMedChem 2021, 1-17, https://doi.org/10.1002/cmdc.202000677.

30. Sanad, S.M.H.; Ahmed, A.A.M.; Mekky, A.E.M. Synthesis, in - vitro and in - silico study of novel thiazoles as potent antibacterial agents and MurB inhibitors. Arch Pharm-DPhG 2020, 353, 1-13, https://doi.org/10.1002/ardp.201900309.

31. Tafti, A.D.; Bi, B. Mirjalili, F.; Bamoniri, A.; Salehi, N. Rapid four - component synthesis of dihydropyrano [ 2, 3 - c ] pyrazoles using nano - eggshell / Ti ( IV ) as a highly compatible natural based catalyst. BMC Chemistry 2021, 15, 1-8, https://doi.org/10.1186/s13065-021-00734-5.

32. Zahouily, M.; Elmakssoudi, A.; Mezdar, A.; Rayadh, A.; Sebti , S.; Lazrek, H. Three Components Coupling Catalysed by Na2CaP2O7: Synthesis of \&\#945;-Amino Phosphonates Under Solvent-Free Conditions at Room Temperature. Lett Org Chem 2005, 9, 2, 428-32, https://doi.org/10.2174/1570178054405887.

33. Mehran , Y.L.; James, L.; Wright , H. Correlating Partitioning and Caco-2 Cell Permeability of Structurally Diverse Small Molecular Weight Compounds. Pharm Res 1998, 15, 1490-3, https://doi.org/10.1023/a:1011930411574.

34. Elick, H.E.S.; Rove, J. MDCK (Madin - Darby Canine Kidney) Cells : A Tool for Membrane Permeability Screening. J Pharm Sci. 1999, 88,18-32, https://doi.org/10.1021/js9803205. 


\section{Supplementary Materials}

We report in Supplementary Material (ESI) additional data from the characterization of the synthesized compounds (see Figures S1-S16) to the antibacterial assays (Figure S 21 ). See also Tables S3 and S4 to have a comprehensive image of toxicological studies (ADMET) performed in silico via Computer-aided Drug Design Tools.

\section{Characterization of the compounds}

6-Amino-3-methyl-4-(2-hydroxyphenyl)-1,4-dihydropyrano[2,3-c] pyrazole-5-carbonitrile 5a

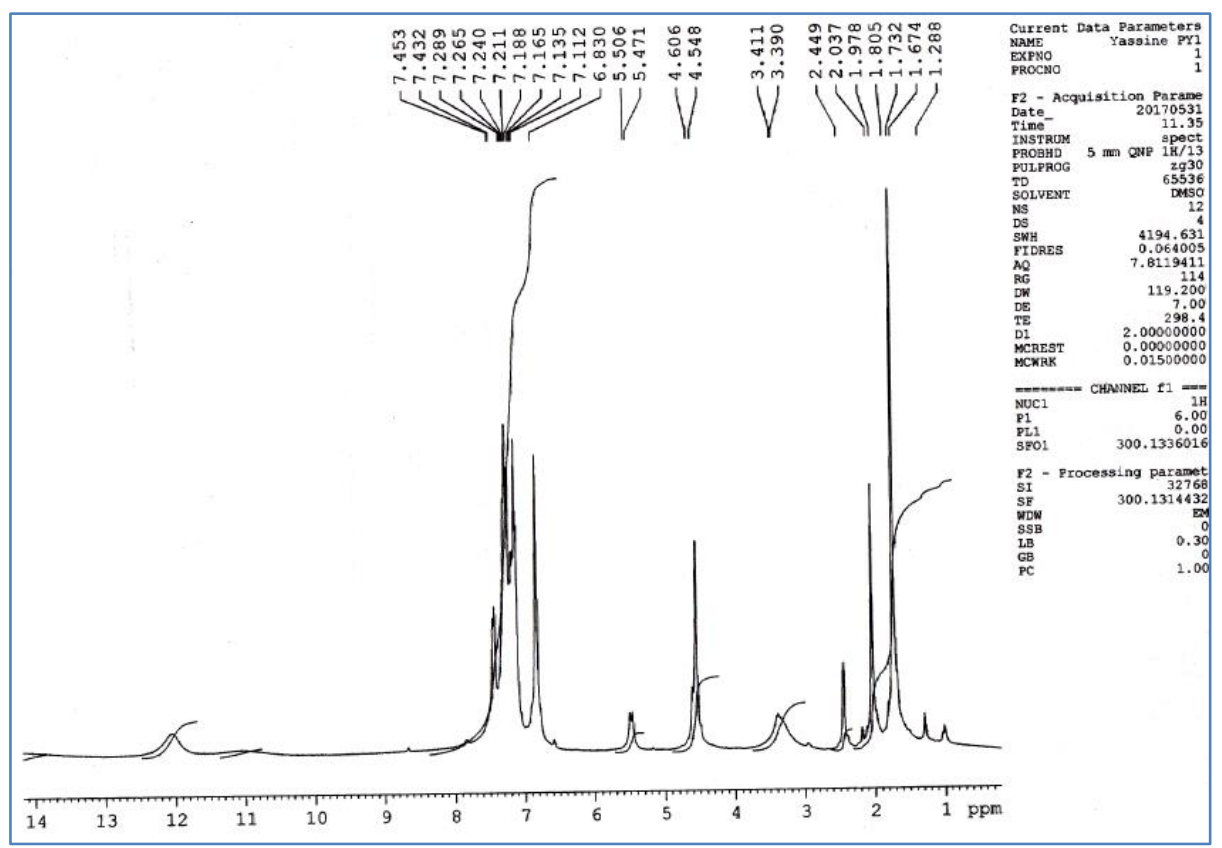

Figure S1. NMR ${ }^{1} \mathrm{H}$ of pyranopyrazoles $5 \mathrm{a}$.

6-Amino-3-methyl-4-(2-hydroxyphenyl)-1,4-dihydropyrano[2,3-c] pyrazole-5-carbonitrile 5b

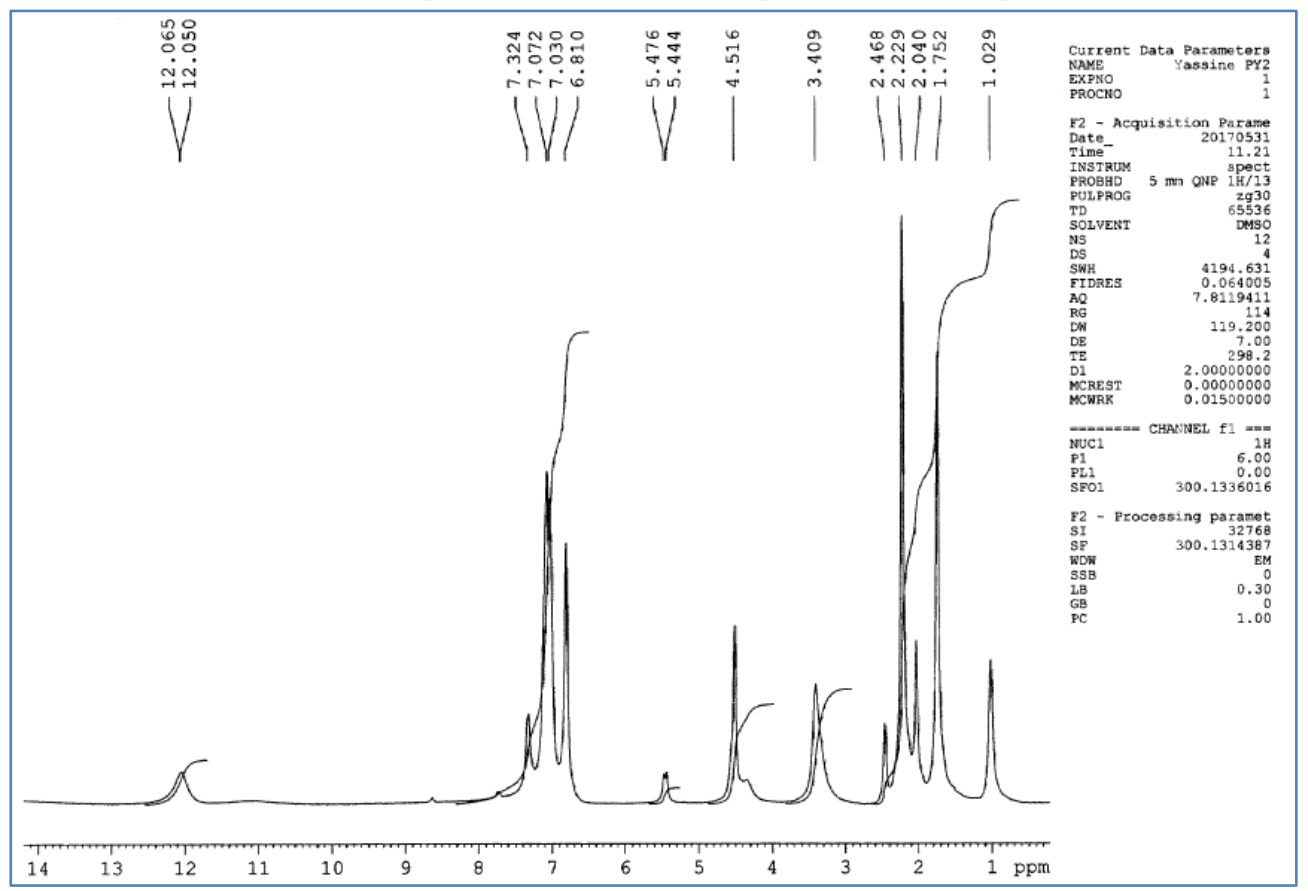

Figure S2. NMR ${ }^{1} \mathrm{H}$ of pyranopyrazoles $5 b$. 
6-Amino-3-methyl-4-(2-hydroxyphenyl)-1,4-dihydropyrano[2,3-c] pyrazole-5-carbonitrile 5c

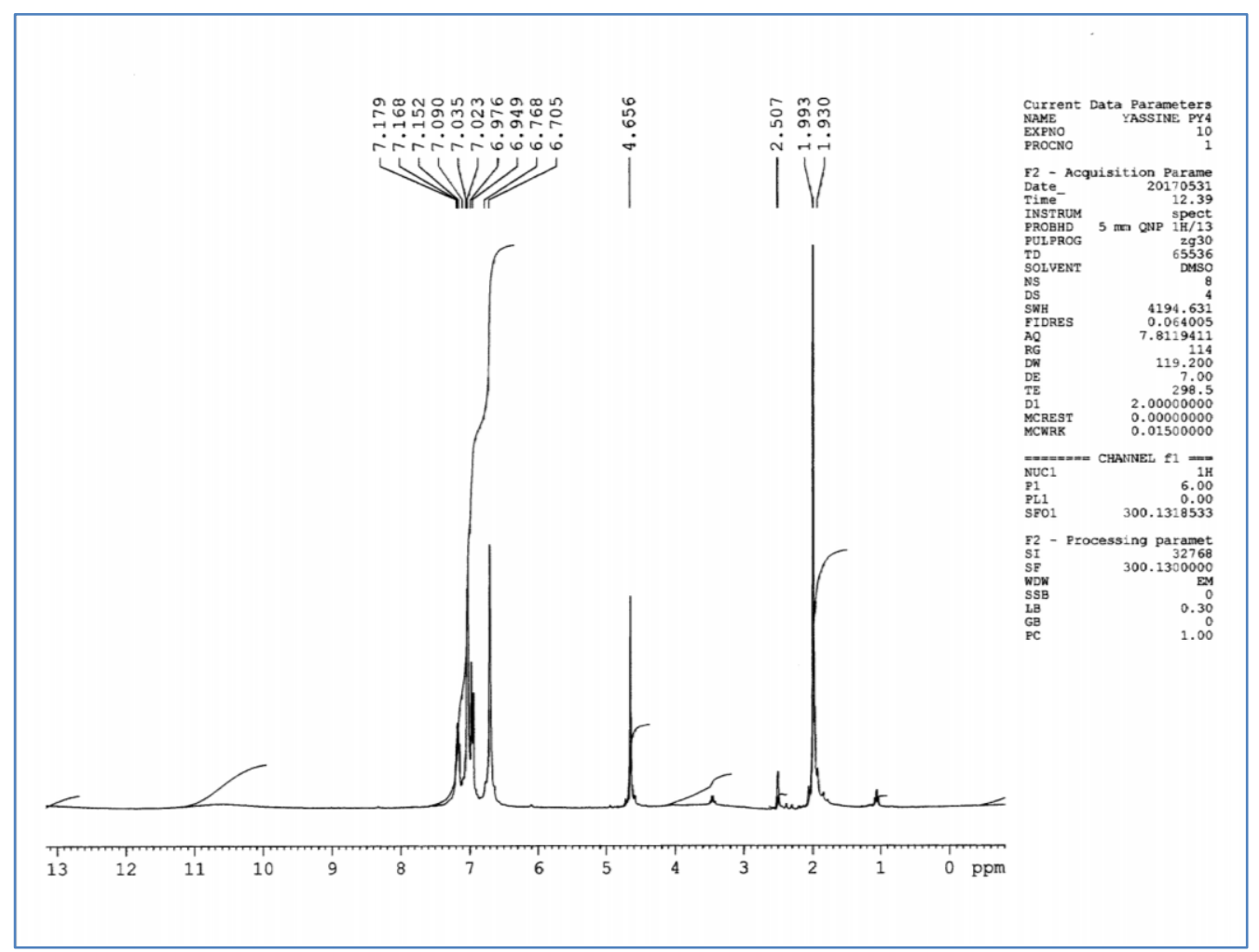

Figure S3. NMR ${ }^{1} \mathrm{H}$ of pyranopyrazoles $5 \mathrm{c}$.

6-Amino-3-methyl-4-(4-methoxyphenyl)-1,4-dihydropyrano[2,3-c] pyrazole-5-carbonitrile 5d

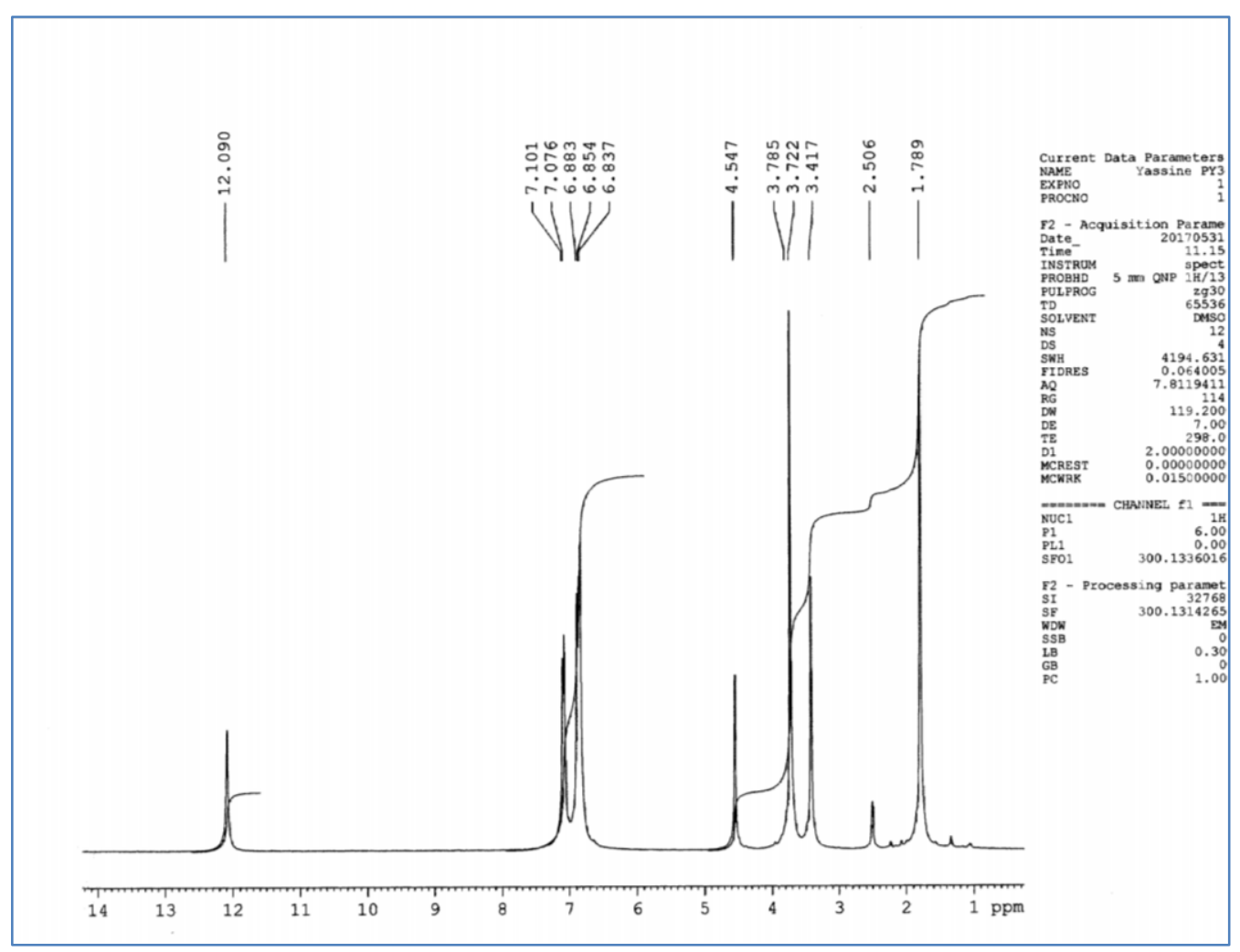

Figure S4. NMR ${ }^{1} \mathrm{H}$ of pyranopyrazoles $5 \mathrm{~d}$. 
6-Amino-3-methyl-4-(4-methoxyphenyl)-1,4-dihydropyrano[2,3-c] pyrazole-5-carbonitrile 5e

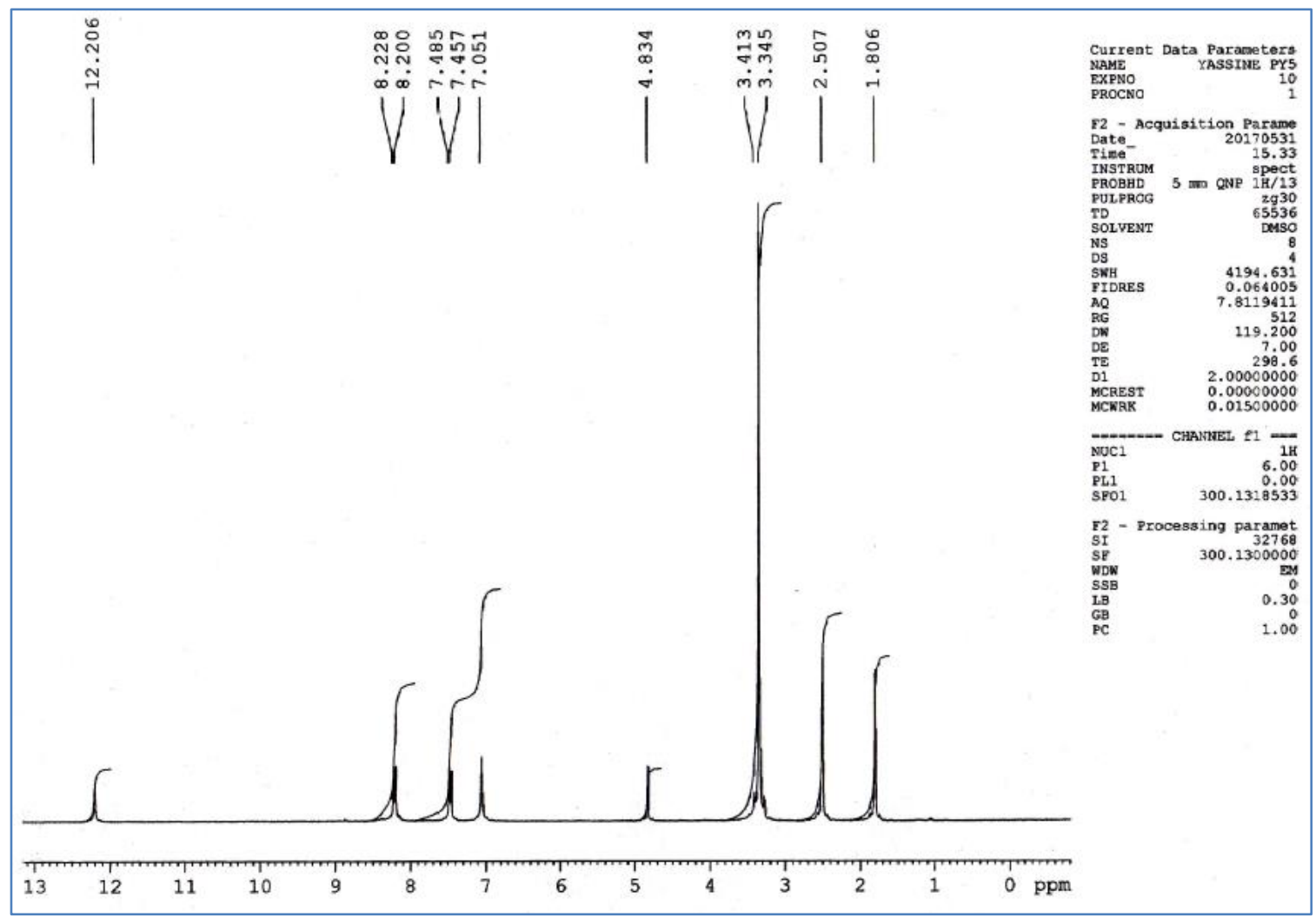

Figure S5. NMR ${ }^{1} \mathrm{H}$ of pyranopyrazoles 5 e.

6-Amino-3-methyl-4-(2-hydroxyphenyl)-1,4-dihydropyrano[2,3-c] pyrazole-5-carbonitrile 5a

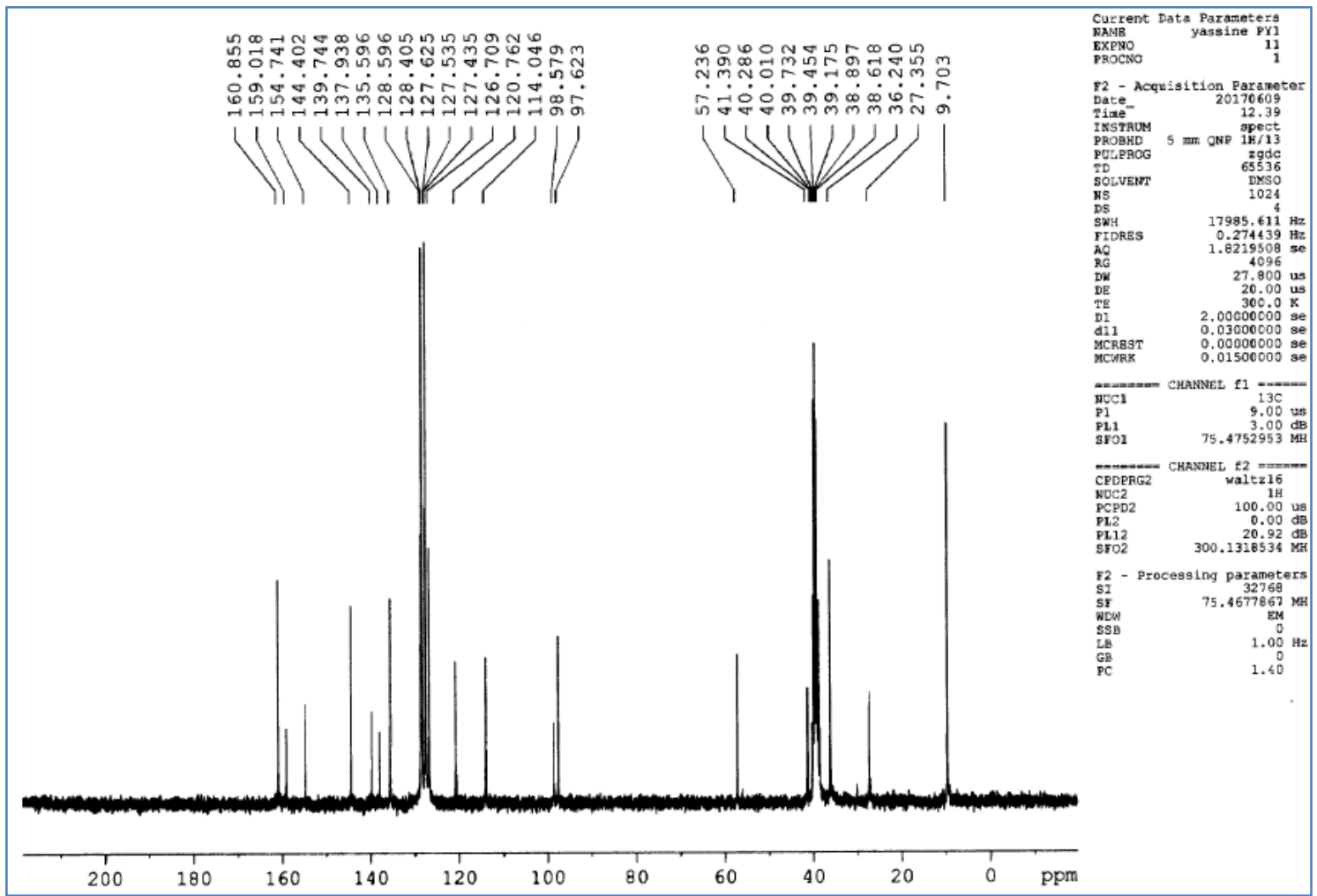

Figure S6. NMR ${ }^{13} \mathrm{C}$ of pyranopyrazoles compound 5a. 
6-Amino-3-methyl-4-(2-hydroxyphenyl)-1,4-dihydropyrano[2,3-c] pyrazole-5-carbonitrile 5b

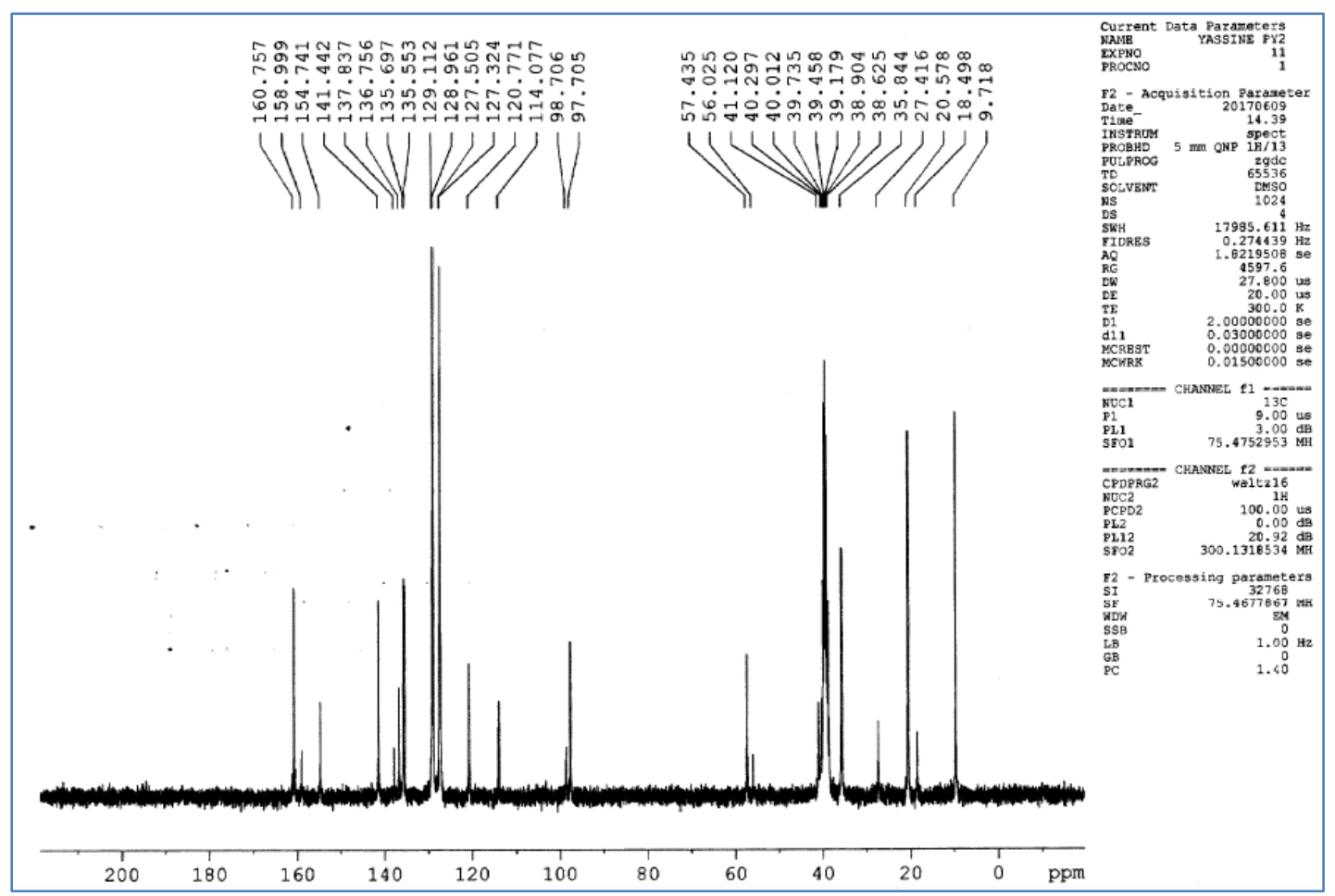

Figure S7. NMR ${ }^{13} \mathrm{C}$ of pyranopyrazoles compound $\mathbf{5 b}$.

6-Amino-3-methyl-4-(2-hydroxyphenyl)-1,4-dihydropyrano[2,3-c] pyrazole-5-carbonitrile 5c

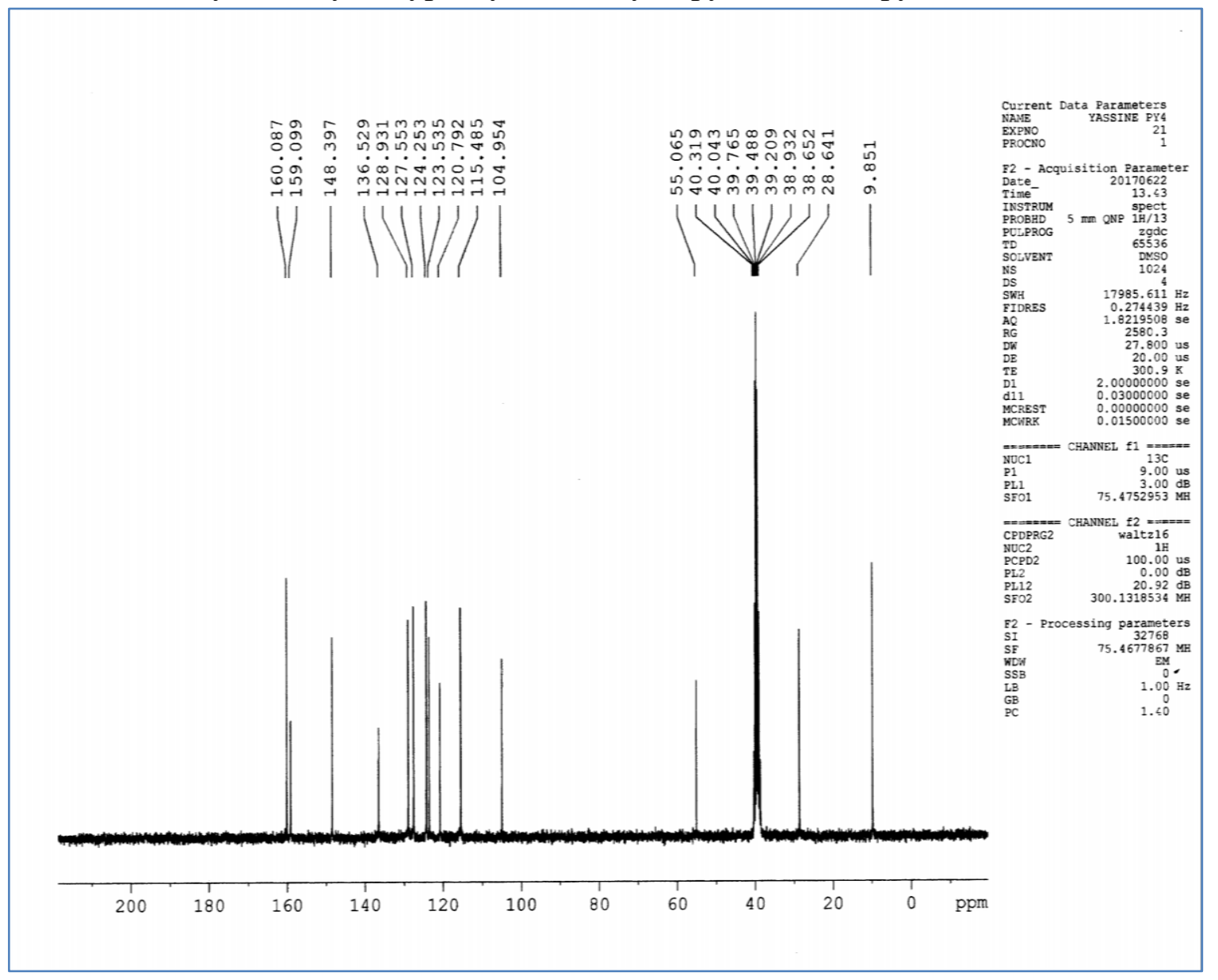

Figure S8. NMR ${ }^{13} \mathrm{C}$ of pyranopyrazoles compound $\mathbf{5 c}$. 
6-Amino-3-methyl-4-(4-methoxyphenyl)-1,4-dihydropyrano[2,3-c] pyrazole-5-carbonitrile

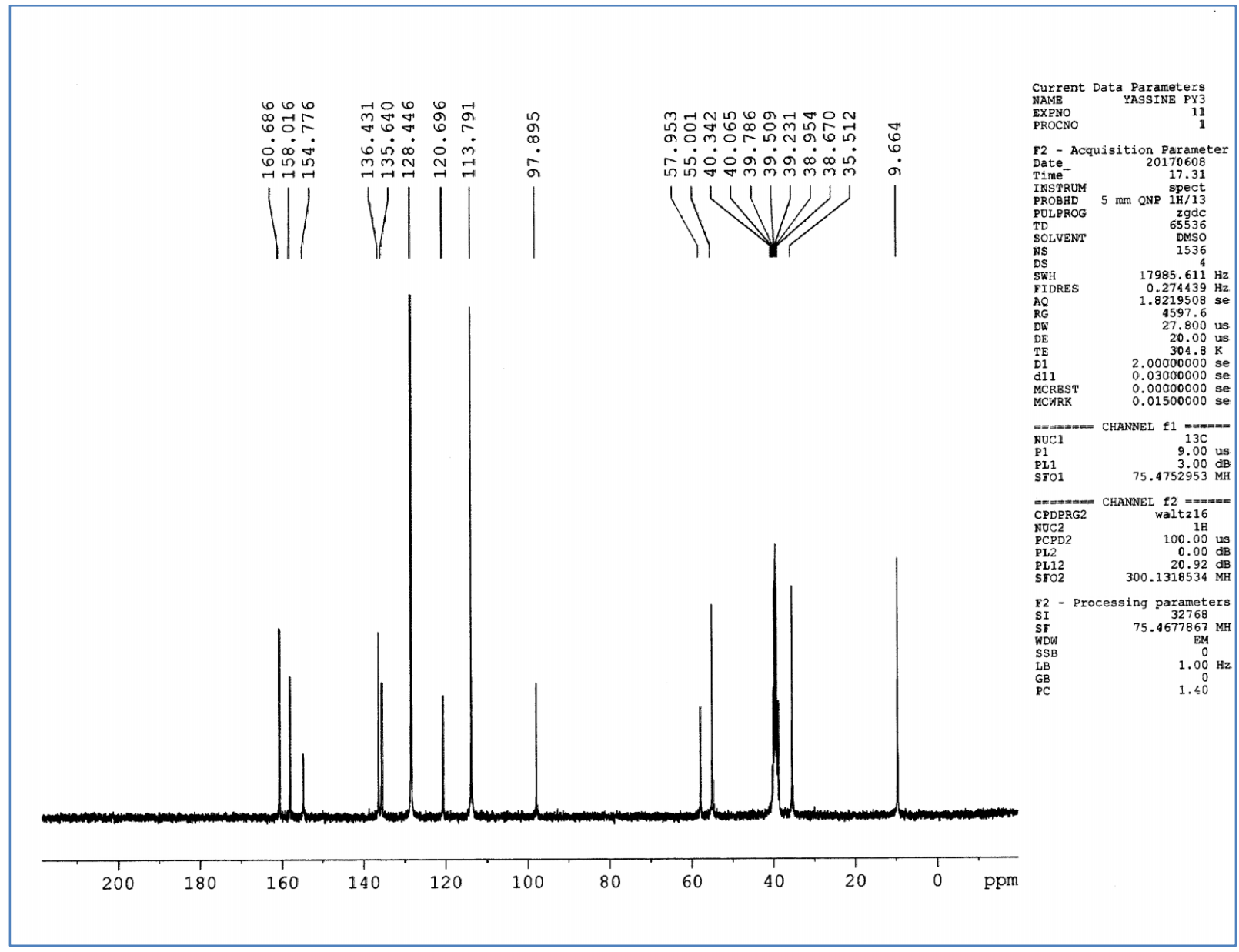

Figure S9. NMR ${ }^{13} \mathrm{C}$ of pyranopyrazoles compound $5 \mathrm{~d}$.

6-Amino-3-methyl-4-(2-hydroxyphenyl)-1,4-dihydropyrano[2,3-c] pyrazole-5-carbonitrile 5e

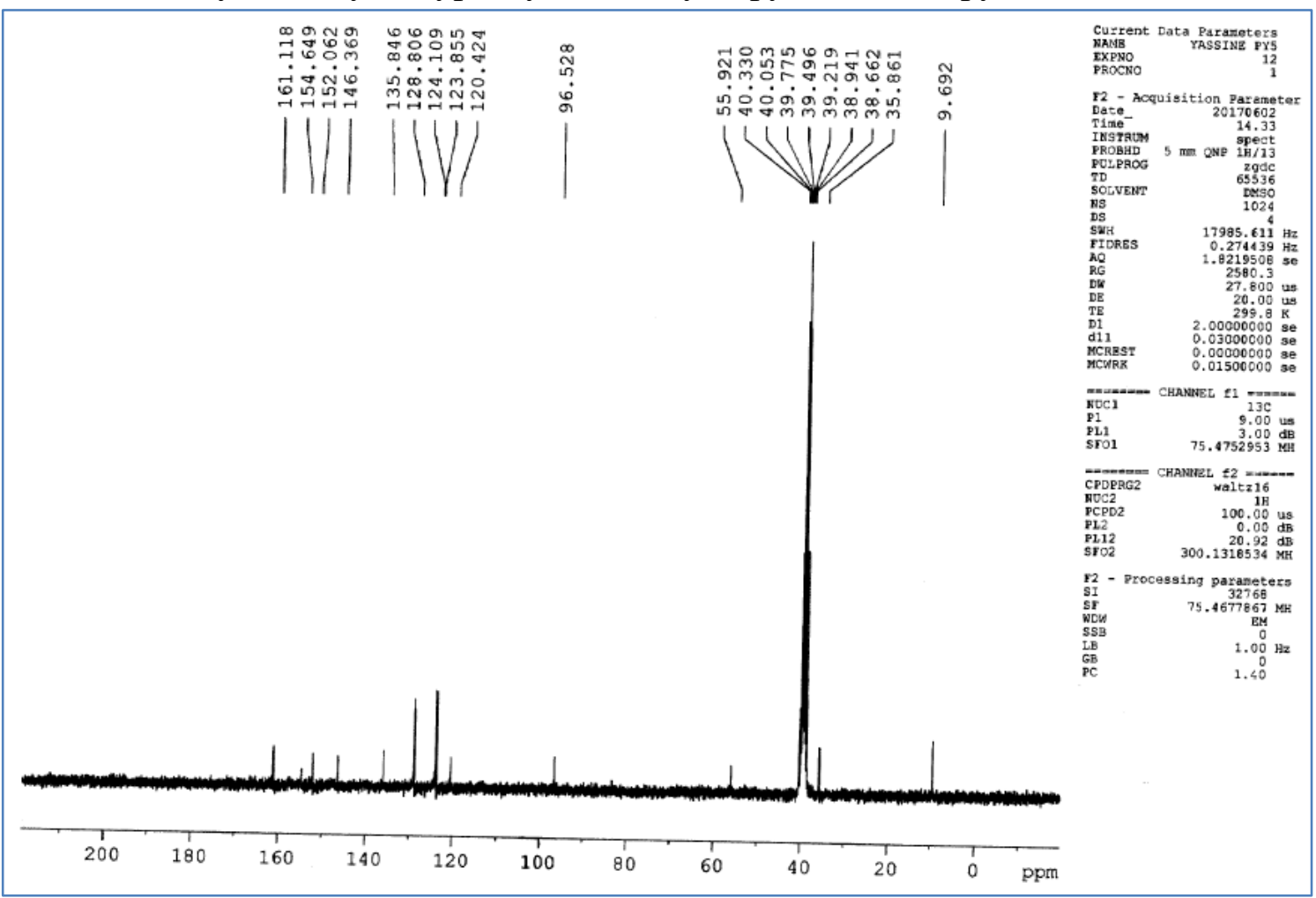

Figure S10. NMR ${ }^{13} \mathrm{C}$ of pyranopyrazoles compound 5e. 
6-Amino-3-methyl-4-(2-hydroxyphenyl)-1,4-dihydropyrano[2,3-c] pyrazole-5-carbonitrile 5a

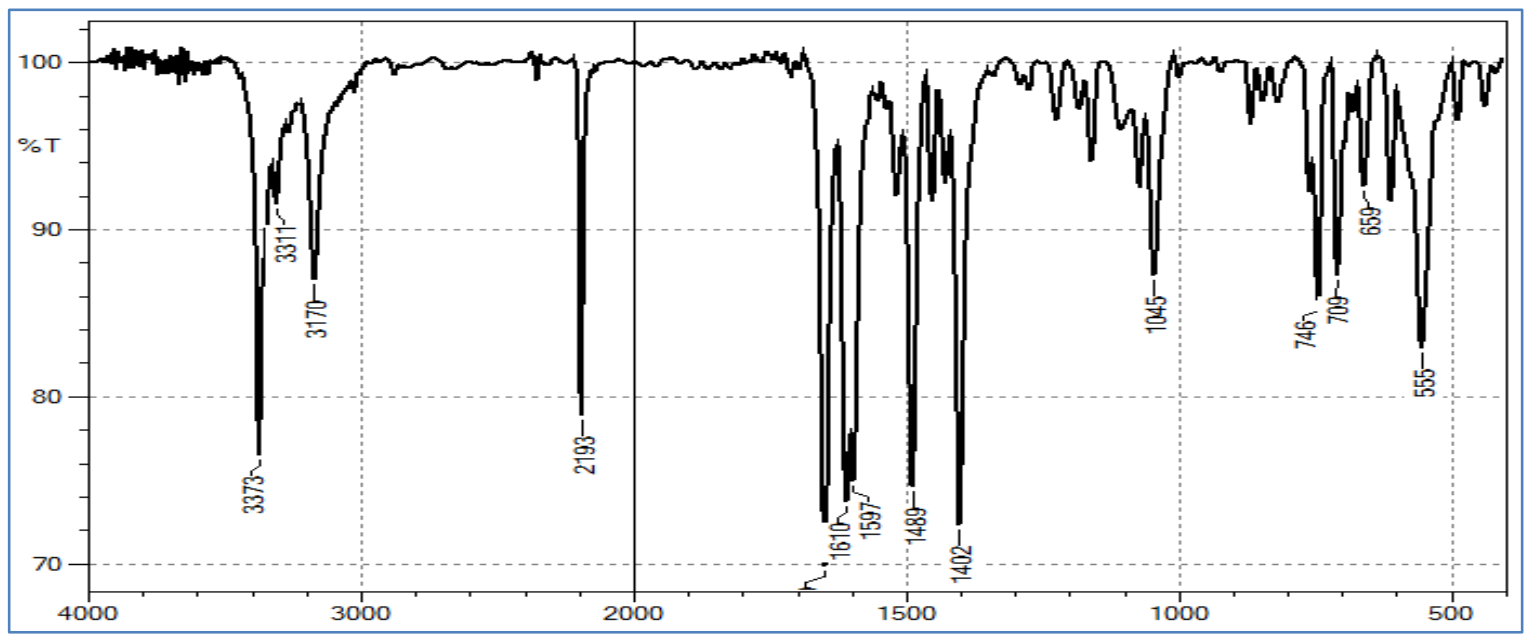

Figure S11. IR pattern of the synthesized compound of $5 \mathbf{a}$.

6-Amino-3-methyl-4-(2-hydroxyphenyl)-1,4-dihydropyrano[2,3-c] pyrazole-5-carbonitrile 5b

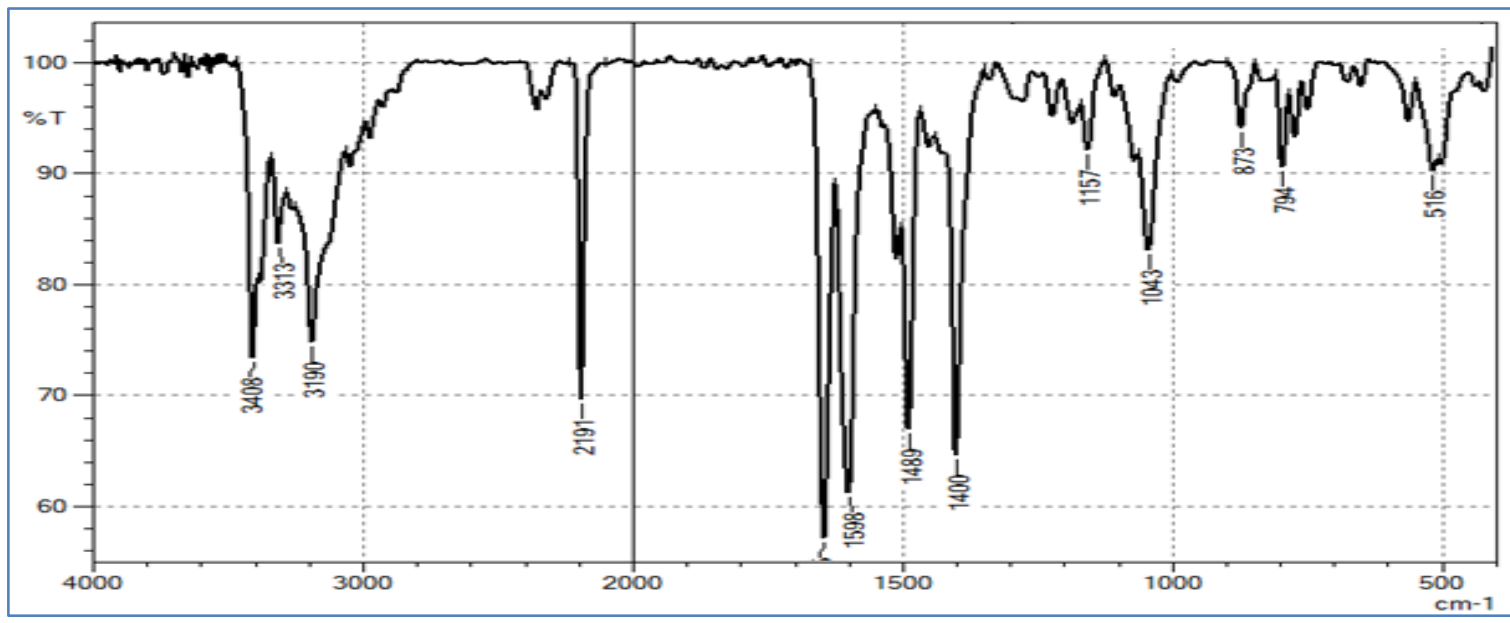

Figure S12. IR pattern of the synthesized compound of $\mathbf{5 b}$.

6-Amino-3-methyl-4-(2-hydroxyphenyl)-1,4-dihydropyrano[2,3-c] pyrazole-5-carbonitrile 5c

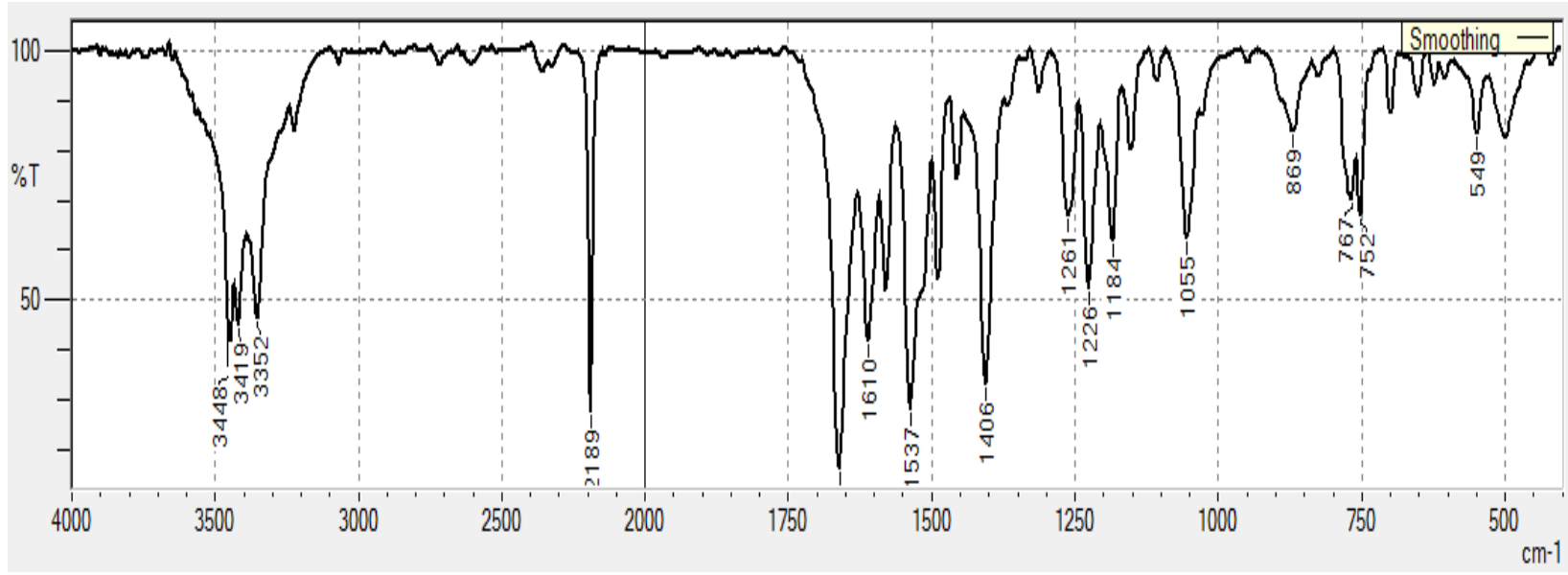

Figure S13. IR pattern of the synthesized compound 5c. 
6-Amino-3-methyl-4-(4-methoxyphenyl)-1,4-dihydropyrano[2,3-c] pyrazole-5-carbonitrile 5d

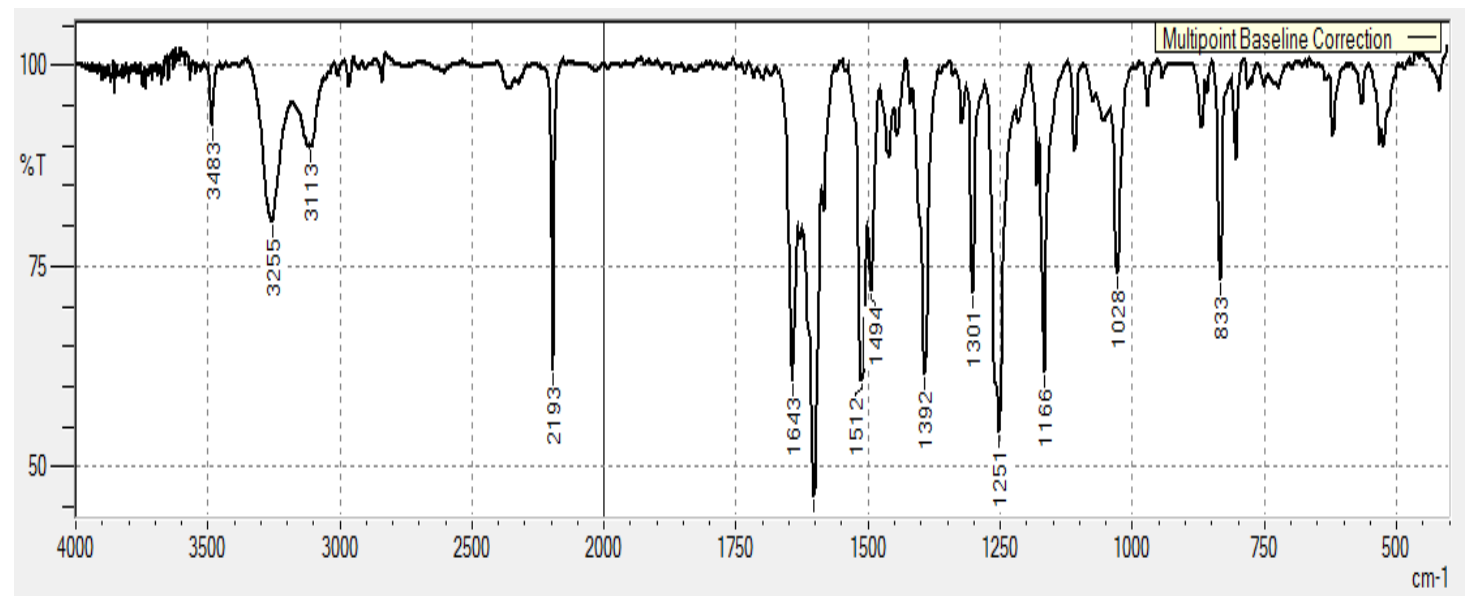

Figure S14. IR pattern of the synthesized compound 5d.

6-Amino-3-methyl-4-(4-methoxyphenyl)-1,4-dihydropyrano[2,3-c] pyrazole-5-carbonitrile 5e

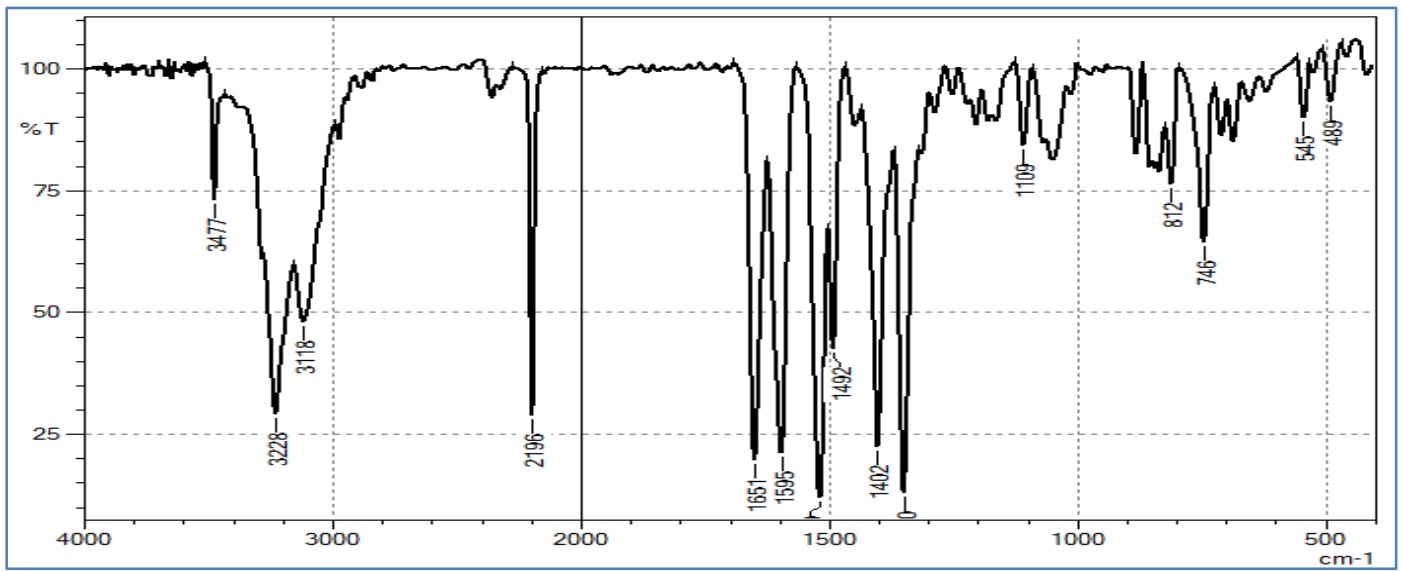

Figure S15. IR pattern of the synthesized compound 5e.

2. HPLC Analyses
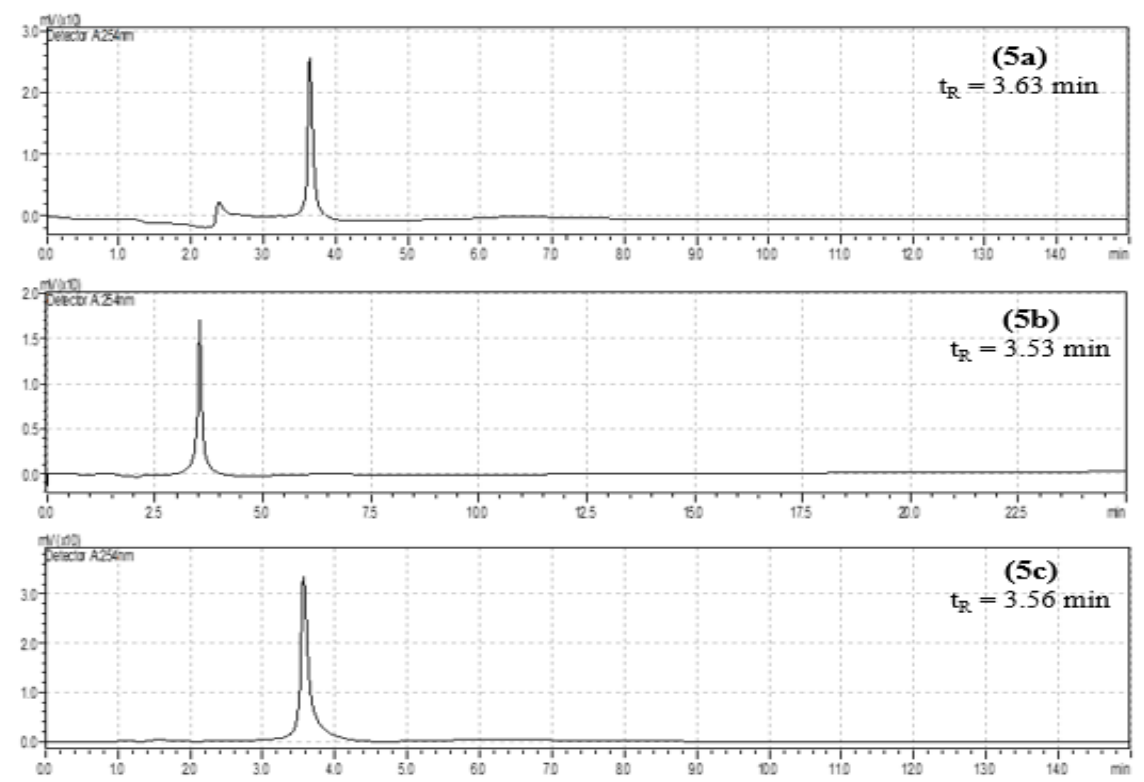

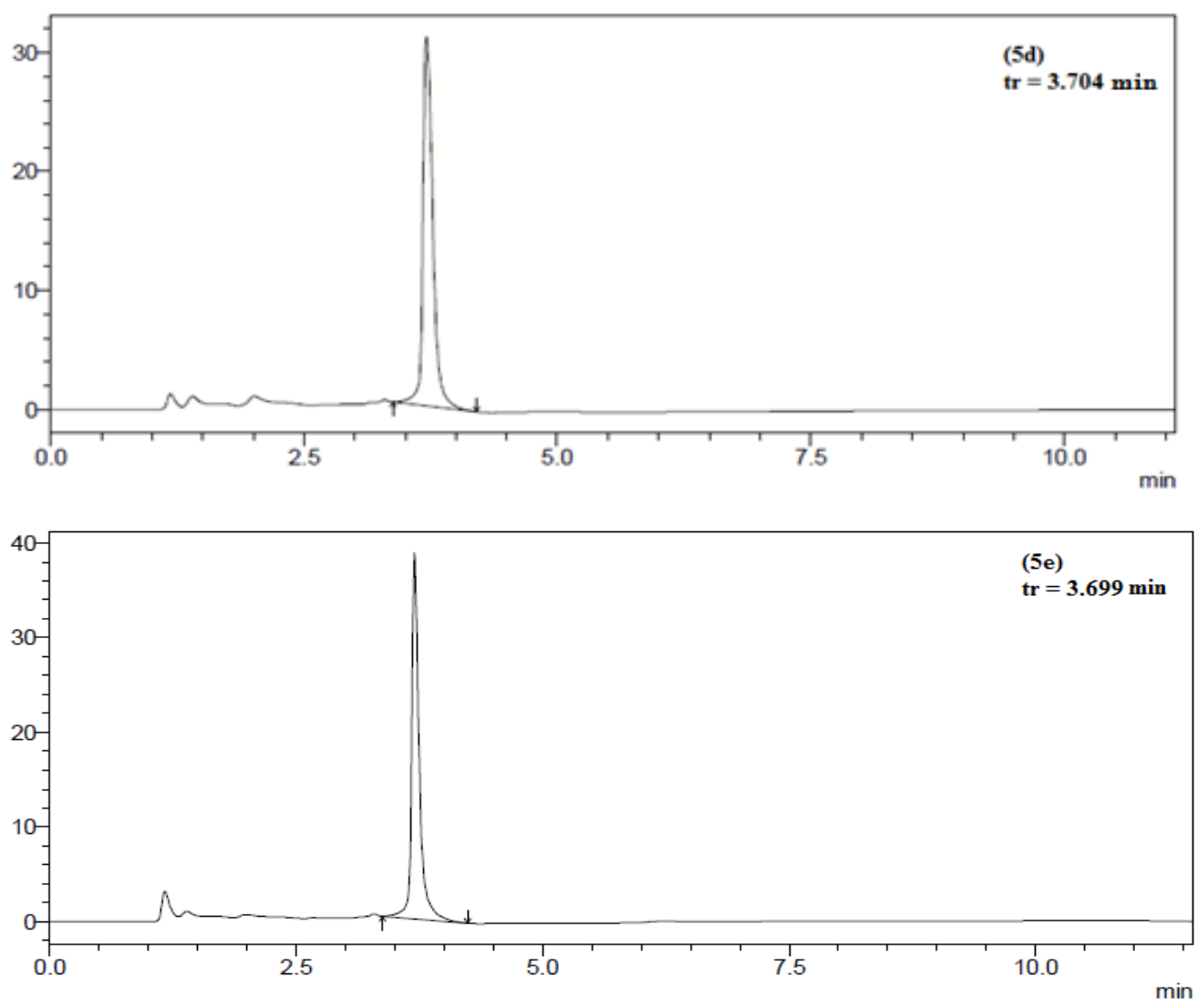

Figure S16. HPLC chromatograms of pyranopyrazoles 5a-e.

\section{Synthesis and characterization of the catalyst}

The diffractometer uses copper anticathode radiation $\mathrm{Cu}-\mathrm{K} \alpha$ radiation: $\lambda=1.5406 \mathrm{~A}^{\circ}$. The crystalline parameters were refined on a computer using the least-squares method via the AFPAR program. The acquisition is carried out at ambient temperature with a scanning mode $\theta / 2$ (and a Bragg angle $\theta$ spanning from $10^{\circ}$ to $50^{\circ}[20]$

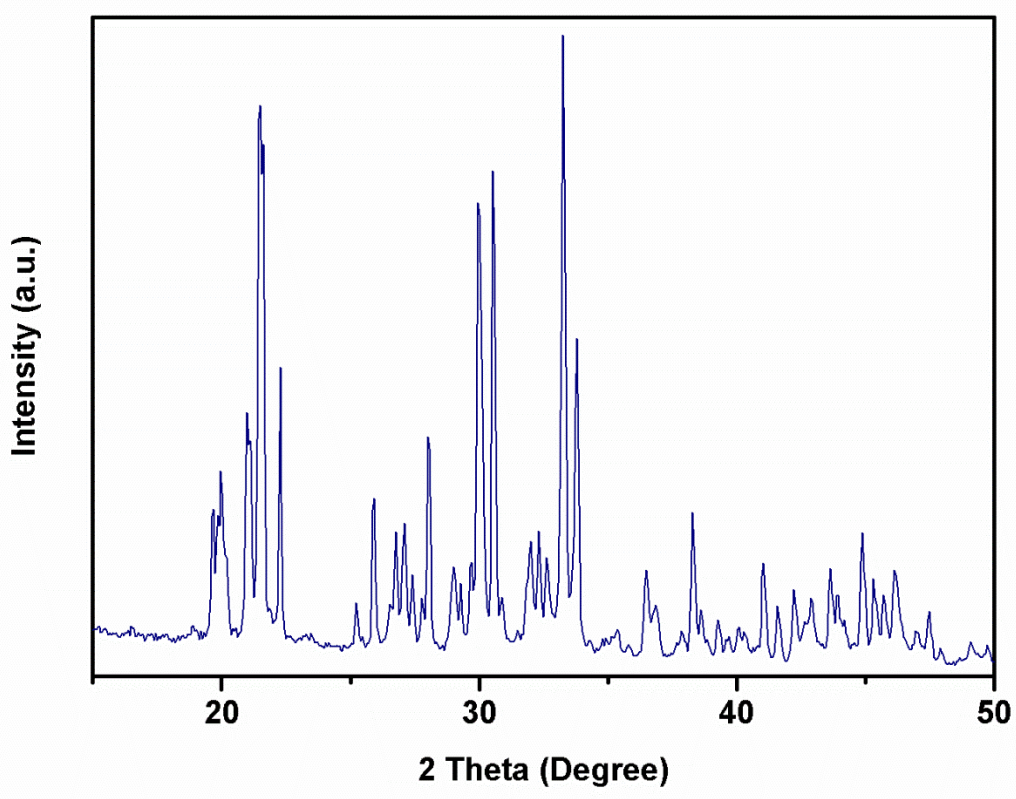

Figure S17. The XDR pattern of the diphosphate $\mathrm{Na}_{2} \mathrm{CaP}_{2} \mathrm{O}_{7}$. 
Table S1. Allotment of the observed bands of $\mathrm{Na}_{2} \mathrm{CaP}_{2} \mathrm{O}_{7}$ analyzed by X-ray diffractometer

\section{Crystallographic data}

\begin{tabular}{c|c}
\hline Space group & Triclinic,PÏ \\
\hline $\mathrm{M}(\mathrm{g} / \mathrm{mol})$ & 260.0 \\
\hline $\mathrm{a}(\AA)$ & 5.361 \\
\hline $\mathrm{b}(\AA)$ & 7.029 \\
\hline $\mathrm{c}(\AA)$ & 8.743 \\
\hline$\alpha\left(^{\circ}\right)$ & 69.4 \\
\hline$\beta\left(^{\circ}\right)$ & 89.02 \\
\hline$\gamma\left(\left(^{\circ}\right)\right.$ & 88.78 \\
\hline $\mathrm{V}\left(\AA^{3}\right)$ & 308.5 \\
\hline $\mathrm{Z}$ & 2
\end{tabular}

\section{Infrared of the catalyst}

The appearance of symmetrical vibration bands of P-O-P at $720 \mathrm{~cm}^{-1}$ and antisymmetric vibration bands at $893 \mathrm{~cm}^{-1}$ confirm the existence of $\mathrm{P}_{2} \mathrm{O}_{7}$ (Figure S19). Two vibration fields have proved the presence of the $\mathrm{PO}_{4}$ group, the first at $996 \mathrm{~cm}^{-1}$ and 1031 $\mathrm{cm}^{-1}$ and the second going from 1130 to $1278 \mathrm{~cm}^{-1}$ [32]

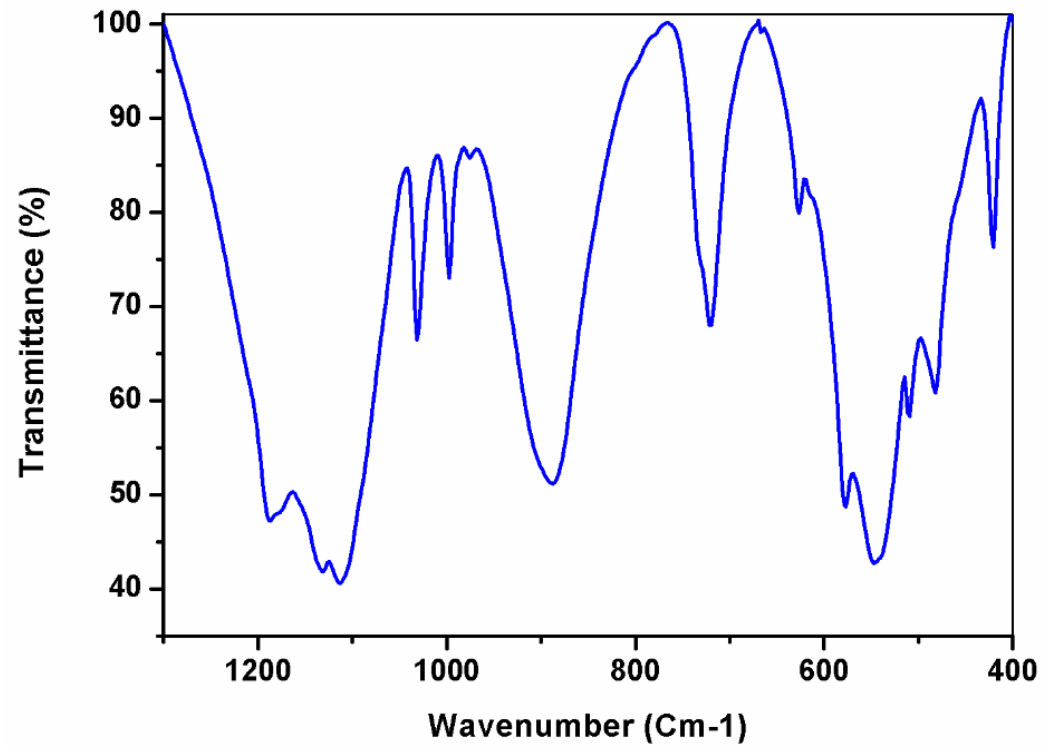

Figure S18. The infrared pattern of the catalyst was measured by using the FITR apparatus.

Table S2. Attribution of the observed bands of $\mathrm{Na}_{2} \mathrm{CaP}_{2} \mathrm{O}_{7}$ analyzed by FTIR spectroscopy.

Observed band $\left(\mathrm{cm}^{-1}\right)$

Awarding

\begin{tabular}{llll}
\hline 407 & & \\
419 & $\delta\left(\mathrm{P}_{2} \mathrm{O}_{7}\right)$ & \\
483 & & \\
511 & & \\
548 & & \\
577 & & \\
626 & & \\
\hline
\end{tabular}




$\begin{array}{cc}720 & v_{\text {sys }}(\mathbf{P}-\mathbf{O}-\mathbf{P}) \\ 893 & \left.\text { vantisys }^{(P-O}-\mathbf{P}\right) \\ 996 & \\ & \\ 1031 & v_{\text {sys }}\left(\mathbf{P 0} \mathbf{0}_{4}\right) \\ 1130 & \\ 1175 & \text { vantisys }(\mathbf{P 0 4}) \\ 1278 & \end{array}$

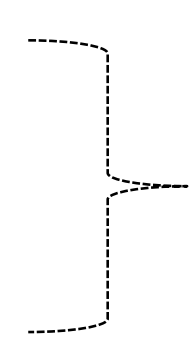

\section{Valence vibrations}

\section{TEM and SEM}
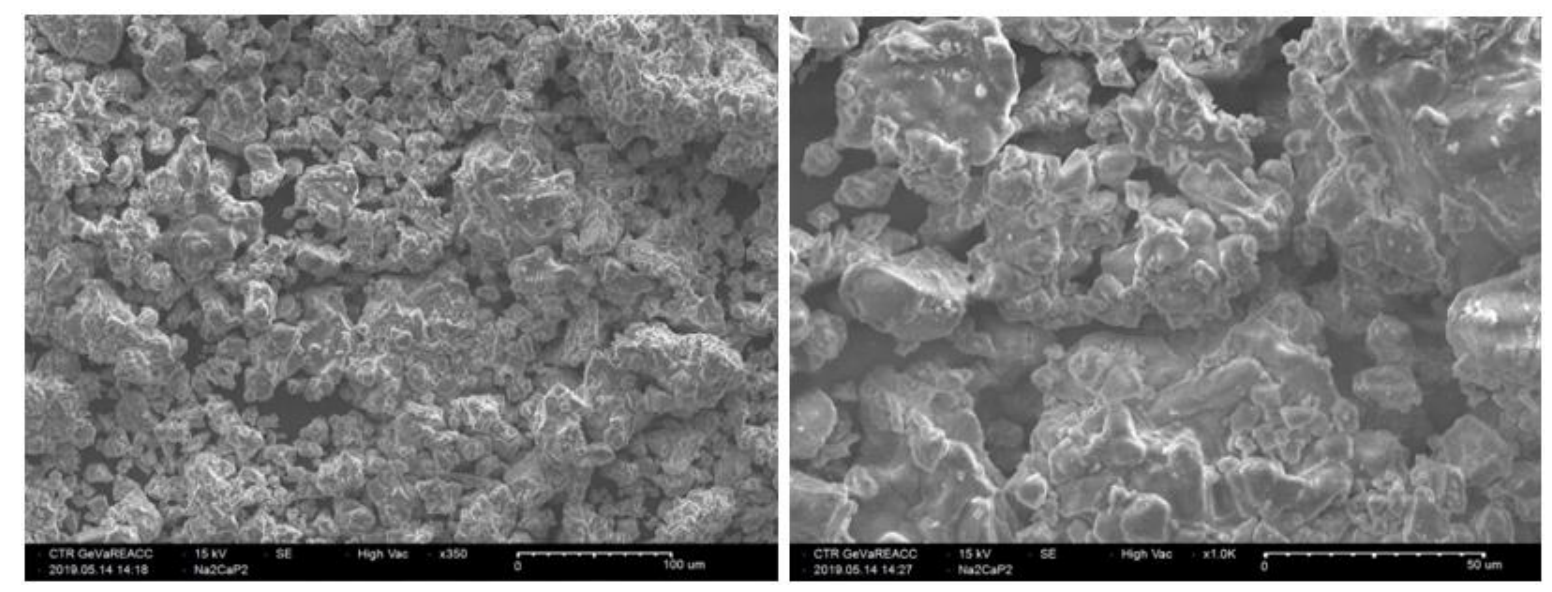

Figure S19. SEM images of $\mathrm{Na}_{2} \mathrm{CaP}_{2} \mathrm{O}_{7}$.
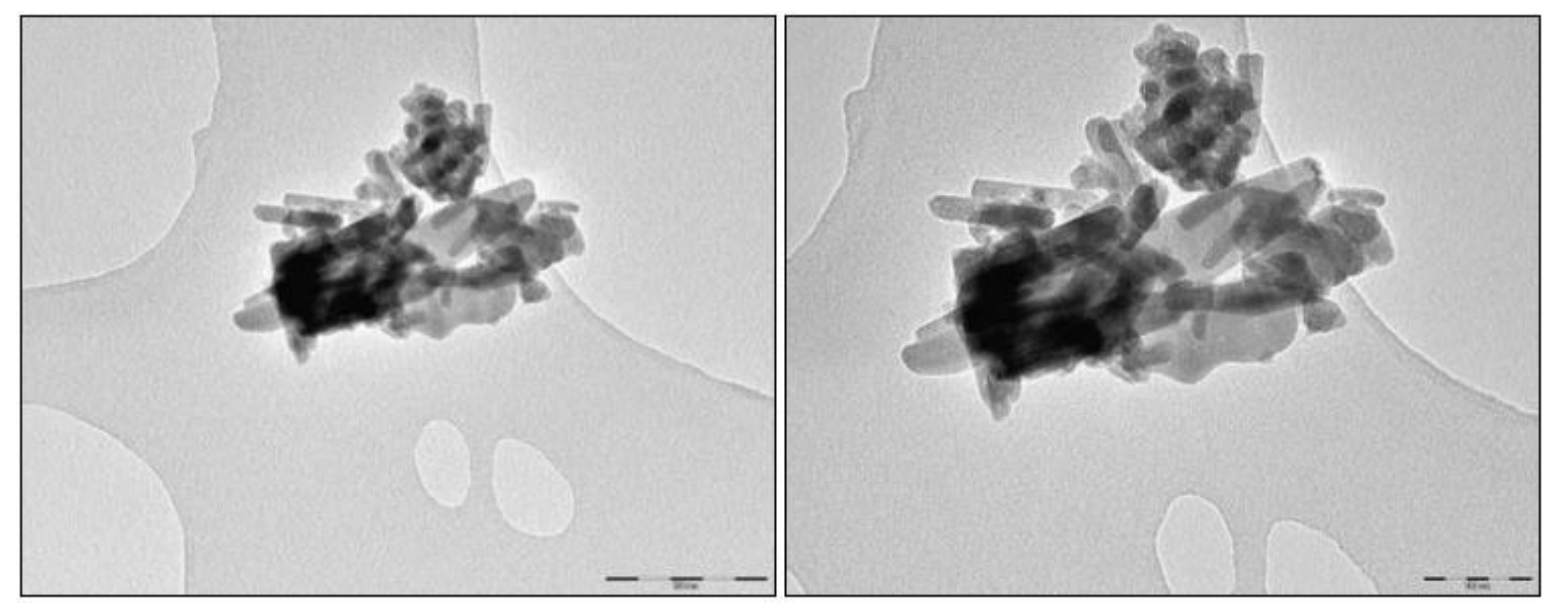

Figure S20.TEM images of $\mathrm{Na}_{2} \mathrm{CaP}_{2} \mathrm{O}_{7}$.

\section{ADMET/TOX screening}

Table S3. In silico physicochemical parameters for good oral bioavailability of synthesized compounds $\mathbf{5}(\mathbf{a}-\mathbf{e})$.

\begin{tabular}{c|c|c|c|c} 
Compounds & Log P & MM & $\begin{array}{c}\text { Hydrogen } \\
\text { bond donor }\end{array}$ & $\begin{array}{c}\text { Hydrogen } \\
\text { bond acceptor }\end{array}$ \\
\hline $\mathbf{5 a}$ & 2.3 & $252.27 \mathrm{~g} / \mathrm{mol}$ & 2 & 4 \\
\hline $\mathbf{5 b}$ & 2.7 & $266.3 \mathrm{~g} / \mathrm{mol}$ & 2 & 4 \\
\hline $\mathbf{5 c}$ & 2.3 & $282.3 \mathrm{~g} / \mathrm{mol}$ & 2 & 5 \\
\hline $\mathbf{5 d}$ & 2 & $268.27 \mathrm{~g} / \mathrm{mol}$ & 3 & 5 \\
\hline $\mathbf{5 e}$ & 2.1 & $297.27 \mathrm{~g} / \mathrm{mol}$ & 2 & 6
\end{tabular}

All the ADMET parameters were found to be favourable for all selected compounds $\mathbf{5}(\mathbf{a}-\mathbf{e})$. 
Table S4. Drug likeness predictions of tested compounds 5(a-e).

\begin{tabular}{c|c|c|c|c|c}
\multicolumn{5}{c}{ Absorption } & \multicolumn{2}{c}{ Distribution } \\
\hline & HIA (\%) & $\begin{array}{c}\text { Cells Caco-2 } \\
\left(\mathbf{n m ~ s e c} \mathbf{~}^{-1}\right)\end{array}$ & MDCK & $\begin{array}{c}\text { Skin } \\
\text { Permiability }\end{array}$ & BBB \\
\hline $5 \mathrm{a}$ & 86.259135 & 8.35134 & 122.163 & -4.29465 & 0.727216 \\
\hline $5 \mathrm{~b}$ & 86.801884 & 0.414056 & 198.378 & -4.23184 & 1.07902 \\
\hline $5 \mathrm{c}$ & 86.421462 & 7.08002 & 56.5433 & -4.43997 & 0.565816 \\
\hline $5 \mathrm{~d}$ & 76.953830 & 21.1136 & 47.9383 & -4.48835 & 0.397176 \\
\hline $5 \mathrm{e}$ & 68.466285 & 17.972 & 31.1239 & -4.3418 & 0.673673 \\
\hline Ampicillin & 81.478448 & 0.630713 & 0.937589 & -5.03574 & 0.0587946
\end{tabular}

HIA: Human intestinal absorption (HIA, \%)

BBB : in vivo blood-brain barrier penetration (C.brain/C.blood)

Caco-2 cell : in vitro Caco-2 cell permeability ( $\mathrm{nm} / \mathrm{sec}$ ) [33]

MDCK: in vitro MDCK cell permeability (Mandin Darby Canine Kidney) [34]

Intestinal absorption has been predicted to be more than $80 \%$ for compounds $\mathbf{5 a}(86.25 \%) \mathbf{5 b}(86.8 \%)$ and $\mathbf{5 c}$ $(86.42 \%)$, which is greater than reference drugs Ampicillin (81.478\%).

\section{Antibacterial activity}

B

A
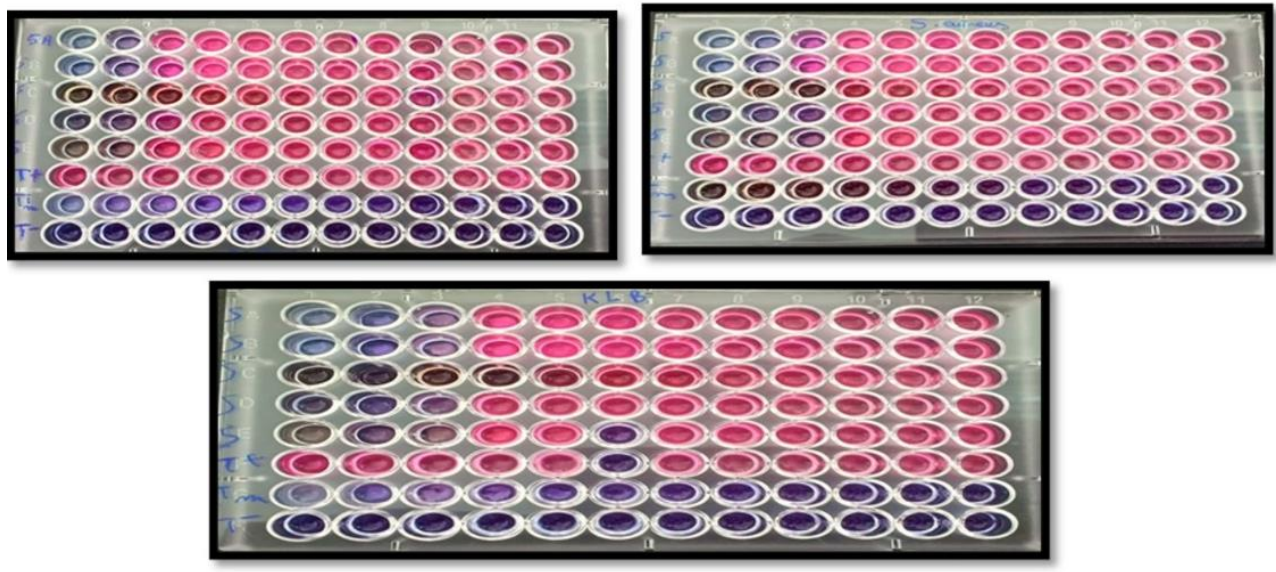

C

Figure S21. Resazurin Dye Test for determining the Minimum Inhibitory Concentration of pyrano[2,3c] pyrazole inoculated with bacterial strains: S. aureus (A), E. coli(B), and K. pneumonia $(\mathrm{C})$. Purple coloration: no change of resazurin coloration reflected the inhibition of bacterial growth. Pink coloration: Reduction of resazurin that can be explained by the metabolic activity of MDR (multidrug-resistant strains). 